\title{
La relación entre política de vivienda y emancipación residencial de la juventud europea
}

\author{
Jordi Bosch Meda
}

Universidad Pompeu Fabra

jordi.bosch-meda@upf.edu

Recepción: 23-07-2015

Aceptación: 16-06-2016

\section{Resumen}

La presente investigación analiza la relación entre el alcance de la política de vivienda dirigida a las personas jóvenes y los niveles de emancipación residencial juvenil en Europa. El estudio se basa en la aplicación del método de la regresión lineal sobre los datos de la encuesta EU SILC entre los años 2006 y 2011. Los resultados muestran que existe una notable correlación entre las tasas de emancipación de cada país y la disponibilidad de vivienda social para las personas jóvenes, así como la implementación de sistemas de ayudas para el pago de la vivienda de la juventud. Ambas variables de política de vivienda explican: a) por separado, el $65 \%$ de la variación en las tasas de emancipación, y b) de forma simultánea - mediante la construcción de un indicador compuesto-, hasta un $74 \%$ de dichas diferencias. En cambio, los indicadores de accesibilidad económica a la vivienda entre las personas jóvenes no mantienen correlación alguna ni con las tasas nacionales de emancipación ni con el grado de desarrollo de la política de vivienda para los jóvenes de cada sistema residencial. En cuanto a la relación entre tasas de emancipación, sistemas de vivienda y modelos de estado de bienestar, se constata la existencia de unos rasgos específicos en cada uno de los distintos modelos existentes — socialdemocrático, liberal, mediterráneo y de transición-, excepto entre los países corporativistas.

Palabras clave: juventud; emancipación juvenil: transición residencial; política de vivienda; sistema de vivienda; estado de bienestar 
Abstract. The Relationship Between Housing Policy and Housing Transitions of Young People in Europe

This research explores to what extent the degree of development of youth housing policy can explain the variation between European countries in the rates of young people not living in the parental home. The study is based on linear regression analyses using EU SILC data from 2006 to 2011. The results show that there is a considerable correlation between the national rates of young people not living with their parents and the two housing policy instruments considered, that is, the availability of social housing and the implementation of housing allowance systems for young people. Both housing policy variables can explain: (i) separately, 65 per cent of the variation in national rates of young people not living in the parental home; and (ii) simultaneously - through the construction of a composite indicator - up to 74 per cent of the variation. By contrast, housing affordability indicators for young people do not show a correlation with either the national rates of young people not living with their parents or with the level of housing policy development for young people. Regarding the relationship between the rates of young people not living in the parental home, housing systems and welfare state regimes, this research confirms the existence of particular features in each model—social-democratic, liberal, Mediterranean, and post-socialist-except among corporatist countries.

Keywords: youth; young people; housing transition; housing policy; housing system; welfare state

\section{Sumario}

Introducción

1. Los modelos de emancipación residencial de la juventud europea desde las tipologías de estado de bienestar y los sistemas de vivienda
2. Estudio comparado de la relación entre política de vivienda y tasas de emancipación residencial de la juventud europea

3. Conclusiones y discusión

Referencias bibliográficas

Anexo I

\section{Introducción}

La transición de la juventud a la vida adulta tiene dos dimensiones fundamentales estrechamente interrelacionadas: a) la residencial-familiar, entendida como el abandono de la vivienda de los progenitores para residir en otra y formar un nuevo hogar, $b$ ) y la económico-laboral, a saber, el paso del sistema educativo al mercado laboral, y que concluye con una inserción en el mismo que permita a la persona alcanzar su independencia económica (Galland, 1991; Jones y Wallace, 1992; Coles, 1995).

Hasta la década de 1980, la emancipación económica y residencial de las personas jóvenes era un proceso, por lo general, relativamente breve, lineal y estandarizado que se daba a edades tempranas de un modo simultáneo y que solía ir asociado a la formación de una familia. Sin embargo, las transforma- 
ciones políticas, sociales y económicas que han tenido lugar desde entonces han modificado profundamente este proceso y, por extensión, el concepto de juventud en sí mismo.

Hoy, los estudios sobre las características de estos procesos de transición a la vida adulta coinciden en su mayor duración (Cote, 2002; Cote y Bynner, 2008), complejidad e incertidumbre, fruto, entre otros factores, de las crecientes dificultades que sufren las personas jóvenes en el mercado laboral y de vivienda, de la fragmentación del estado y la familia como instituciones (Beck y Beck-Gernsheim, 2002; Chandler et al., 2004), así como de los riesgos inherentes a las sociedades postindustriales para conseguir empleo estable y poder formar una familia (Brannen et al., 2002; Taylor-Gooby, 2004; Smith, 2009).

A raíz de estos cambios, la transición juvenil ya no sigue un desarrollo lineal, sino que se ha convertido en un proceso dinámico frecuentemente reversible, tanto a nivel residencial (regreso al hogar paternal, las denominadas trayectorias yo-yo o búmeran) como en el plano económico-laboral (alternancia de periodos de autonomía con otros de precariedad, y dependencia económica hacia el estado o la familia, principalmente) (EGRIS, 2001; Pais, 2003; Biggart y Walther, 2006). Todo ello ha producido una creciente disociación entre emancipación económica y emancipación residencial, la desestandarización de los procesos de formación de nuevos hogares y de adquisición de la autonomía económica (Buchmann, 1989; Shanahan, 2000; Brückner y Mayer, 2005; Elzinga y Liefbroer, 2007; Furlong y Cartmel, 2007; Kohli, 2007; Widmer y Ritschard, 2009), así como un aumento del riesgo de marginalización asociado a la transición juvenil (Valentine, 2003; Furlong y Cartmel, 2007).

Otro elemento clave para comprender los procesos de transición a la vida adulta en la actualidad es el individualismo. En este entorno incierto y cambiante, la potestad de cada joven para tomar sus propias decisiones e idear sus estrategias de emancipación en función de sus preferencias, de los riesgos que desee asumir y de sus recursos personales, familiares, laborales y públicos disponibles, adquiere una gran relevancia. Este auge del individualismo como variable explicativa de los procesos de transición de la juventud ha llevado a algunos autores a hablar de itinerarios vitales o biografias elegidas en lugar de usar el término emancipación (Walther, 2006; Mandic, 2008), así como a expandir el planteamiento individualista como forma de análisis de dichos procesos de transición a la vida adulta. En este marco teórico, Evans y Furlong (1997) acuñaron el término individualismo estructural para describir la tensión existente entre la toma de decisiones (y riesgos) de las personas jóvenes respecto a sus transiciones y a los condicionantes sociales.

En contraposición con el enfoque individualista, el enfoque estructuralista o contextual pone el énfasis en los aspectos culturales, sociales, político-institucionales y económicos para explicar las diferentes pautas de emancipación residencial entre países y regiones (Vogel, 2002; Mandic, 2008). A pesar de la creciente desestructuración e individualización de los procesos de emancipación juvenil, las diferencias entre países siguen siendo notables debido a factores de índole estructural sobre los cuales la persona joven no tiene control alguno. En 
este sentido, buena parte de la investigación comparada de corte estructuralista en esta materia ha estudiado los patrones de emancipación europeos desde aspectos tan diversos como el modelo de formación de hogares (Iacovou, 2002; Berthaud y Iacovou, 2004), el mercado laboral y el sistema educativo (Breen y Buchmann, 2002; Feijten y Mulder, 2005), el tipo de régimen y alcance del estado de bienestar, el papel de la familia en el mismo (Vogel, 2002; Walther, 2006; Van de Velde, 2008; Anxo et al., 2010) o el sistema de vivienda (Andersson, 2002; Mandic, 2008; Anxo et al., 2010; Nico, 2013).

En este contexto, el objetivo del presente estudio es analizar desde un planteamiento estructuralista hasta qué punto el grado de desarrollo de la política de vivienda dirigida a las personas jóvenes puede explicar las diferentes tasas de emancipación residencial juvenil de los países europeos, así como conocer cuál es su relación con las diferentes tipologías de estado de bienestar.

\section{Los modelos de emancipación residencial de la juventud europea desde las tipologías de estado de bienestar y los sistemas de vivienda}

Dentro de la Unión Europea, existen diferencias sustanciales en la edad media de emancipación. Numerosos estudios coinciden en que las personas jóvenes de los países del norte se emancipan mucho antes que las del sur (Breen y Buchmann, 2002; Vogel, 2002; Allen et al., 2004; Schizzerotto y Luchini, 2004). Pero, más allá de esta simple distinción norte-sur, algunos trabajos han identificado diferentes modelos de emancipación en Europa. Por ejemplo, en el contexto de la UE-15, Iacovou (2002) sostiene la existencia de tres modelos de formación de hogares:

1. El nórdico, propio de los países escandinavos y Holanda, que se caracteriza por un temprano abandono del hogar paternal y por una amplia diversidad de opciones residenciales no vinculadas al matrimonio, como la formación de hogares unipersonales y la cohabitación con la pareja fuera del matrimonio.

2. El modelo del sur de Europa, formado por Grecia, Italia, Portugal y España, el cual se caracteriza por una emancipación residencial tardía, por lo general, ligada a la formación de una pareja y el matrimonio.

3. El modelo del norte de Europa, constituido por el resto de países de la UE-15, el cual ocupa una posición intermedia entre los dos anteriores, tanto en la edad de emancipación como en la diversidad de opciones residenciales y familiares de las personas jóvenes emancipadas.

Sin embargo, un corpus importante de la investigación comparada europea en este campo (Breen y Buchmann, 2002; Iacovou, 2002, 2004; Walther, 2006; Mandic, 2008; Buchmann y Kriesi, 2011), en lugar de definir una tipología de procesos de emancipación de la juventud europea, ha analizado las características de estos dentro de cada uno de los modelos de estado de bienestar a partir, por lo general, de la clasificación de Esping-Andersen (1990) (modelos nórdico, corporativista y liberal), seguramente el trabajo más 
influyente sobre esta cuestión, ampliada posteriormente con el modelo mediterráneo o rudimentario (Leibfried, 1992; Ferrera, 1996) y con el de transición o postsocialista (Kornai, 1992). Al respecto, es necesario recordar que, por lo general, las diferentes clasificaciones de modelos de estado de bienestar no han considerado los sistemas de vivienda, sino que, como Esping-Andersen (1990), se han basado en aspectos como el mercado de trabajo, los sistemas de seguridad social y el modelo fiscal. En consecuencia, el modelo de estado de bienestar de cada país, aunque nos da pautas sobre sus características, no nos sirve para explicar directamente su sistema de vivienda (Stephens et al., 2010). Asimismo, los patrones de emancipación están condicionados por factores estructurales más amplios (entre los que se incluye el sistema de vivienda) que los considerados en la clasificación de modelos de estado de bienestar. No obstante, a pesar de estas limitaciones, constituye una potente herramienta a partir de la cual estudiar los diferentes patrones de emancipación europeos.

Por otro lado, la literatura especializada en sistemas de vivienda también ha elaborado sus propias clasificaciones. Algunos autores han centrado sus trabajos en la relación entre sistemas de vivienda y modelos de estado de bienestar (Castles y Ferrera, 1996; Castles, 1998; Kemeny, 2001; Matznetter, 2002; Hoekstra, 2003; Fahey y Norris, 2009, 2011), otros, en la estructura de la producción residencial (Barlow y Duncan, 1994), pero probablemente el peso de los diferentes regímenes de tenencia ha sido el aspecto empleado con más frecuencia para elaborar estas clasificaciones (Kemeny, 1995, 2005; Harloe, 1995; Balchin, 1996; Castles y Ferrera, 1996; Castles, 1998; Allen, 2006). De entre todas las clasificaciones centradas en la tenencia de la vivienda, Kemeny $(1995,2005)$ ha desarrollado el trabajo más influyente de todos. Este se basa en el parque de alquiler social y clasifica los países en dos tipos: los sistemas unitarios y los sistemas duales. Los unitarios son aquellos en los que el segmento del alquiler social, por su mayor tamaño y sistema de adjudicación no orientado exclusivamente a los colectivos desfavorecidos sino a un amplio espectro de la población (universal), domina e influye sobre el resto del mercado de alquiler, de modo que todo este se comporta de forma unitaria. Los países nórdicos, Holanda y Alemania, suelen clasificarse como países con sistemas de vivienda unitarios en los términos de Kemeny. En cambio, los duales son aquellos en los que la vivienda en propiedad es la opción mayoritaria, mientras que el alquiler social es menor y se dirige principalmente a las personas en riesgo de exclusión, asumiendo un papel de red de seguridad, de modo que el comportamiento del alquiler privado y el social son muy diferenciados (duales). Este tipo es característico de los sistemas de vivienda liberal (Reino Unido, Irlanda) y de los del sur y este de Europa.

Por su parte, la relación entre sistemas de vivienda y emancipación también ha recibido la atención del mundo académico. Un problema característico que sufre la juventud para acceder a una vivienda es su peor situación en el mercado en términos de accesibilidad económica (Aassve et al., 2002, Iacovou, 2002; Mulder et al., 2002). Esta vulnerabilidad socioeconómica de la juventud explica su mayor inclinación por la vivienda en alquiler, ya que se 
adapta mejor a las vicisitudes de esta etapa de la vida (Kendig, 1990; McKee, 2012), por lo que los sistemas de vivienda con un escaso parque de alquiler tienden a tener bajas tasas de emancipación, y a la inversa (Aassve et al., 2002; Iacovou, 2002; Mulder, 2006; Mulder et al., 2002; Nico, 2013). Asimismo, numerosos estudios sugieren que aquellos sistemas residenciales cuya política de vivienda contribuye a minimizar los problemas que la juventud debe encarar en sus transiciones residenciales facilitan la emancipación juvenil y viceversa, de modo que los diferentes patrones de emancipación pueden incluso llegar a deducirse a partir de los obstáculos o de las facilidades que las personas jóvenes encuentran en cada sistema residencial (Andersson, 2002; Mandic, 2008; Anxo et al., 2010; Nico, 2013). Lamentablemente, la evolución más reciente de los sistemas de vivienda europeos está marcada por la pérdida de peso del alquiler, el incremento del esfuerzo económico necesario para acceder a una vivienda y una reducción generalizada del alcance de la política de vivienda (CECODHAS, 2012; Pittini, 2012). En suma, por un incremento de los obstáculos para que la población pueda hacer efectivo el derecho a una vivienda.

Gracias a toda esta literatura sobre emancipación, vivienda y estado de bienestar, y a la información estadística disponible, podemos sintetizar a continuación las principales características de cada modelo.

\subsection{El modelo de emancipación socialdemocrático}

El modelo de emancipación socialdemocrático se basa en un amplio compromiso político y social para garantizar el derecho de la juventud a gozar de autonomía e independencia. La robustez del estado de bienestar socialdemocrático, las condiciones de sus mercados laborales, con unas tasas de desempleo juvenil tradicionalmente bajas, sumadas a la flexibilidad de unos sistemas educativos que favorecen la compatibilidad de los estudios con trabajos a tiempo parcial permiten afrontar el proceso de emancipación a edades tempranas sin apenas riesgo de caer en la pobreza (Walther, 2006).

Las características del sistema socialdemocrático de vivienda también contribuyen a facilitar la transición residencial de las personas jóvenes. Estos países suelen tener un bajo porcentaje de hogares propietarios de su vivienda, y grandes parques de alquiler privado y social, y en Suecia y, en menor medida, en Dinamarca, también un considerable porcentaje de vivienda cooperativa (Laino y Pittini, 2011). Según la clasificación de Kemeny, se trata de sistemas unitarios. Además, el método de ayudas para el pago de la vivienda acostumbra a ser amplio, lo que acaba propiciando unos bajos niveles de exclusión residencial y de personas sin techo (Laino y Pittini, 2011; Fitzpatrick y Stephens, 2007a, 2007b).

Sin embargo, desde finales del siglo xx, el sistema socialdemocrático de vivienda ha sufrido importantes cambios. En la mayoría de países, la propiedad ha aumentado (Andrews et al., 2011; Laino y Pittini, 2011), el presupuesto en política de vivienda se ha reducido y, en consecuencia, también el volumen de ayudas para el pago de la vivienda, perdiendo gran parte de su carácter universal 
(Lieberg, 2013). Por ejemplo, estos recortes han generado en Suecia un estancamiento en la oferta de nuevas residencias sociales (Laino y Pittini, 2011), lo que ha repercutido negativamente en los procesos de emancipación. Según Enström (2009), la capacidad económica de la familia es hoy el factor más determinante en las condiciones residenciales de la juventud sueca. Otra consecuencia de estas dificultades es la expansión del fenómeno denominado generación boomerang. Cada vez más personas jóvenes suecas, tras una separación o un divorcio, después de perder el empleo o finalizar sus estudios, ante la insuficiencia de las ayudas públicas, se ven obligadas a regresar a casa de sus progenitores (Lieberg, 2013). No obstante, a pesar de este retroceso en materia de políticas de vivienda, los sistemas socialdemocráticos aún gozan de unos parques de residencia social y de unos sistemas de ayudas para el pago de los domicilios muy superiores a la mayor parte de países europeos (Laino y Pittini, 2011).

\subsection{El modelo de emancipación continental o corporativista}

En los países corporativistas, las personas jóvenes tienden a emanciparse residencialmente antes que en los países mediterráneos o postsocialistas, pero algo más tarde que en los socialdemocráticos (gráfico 1). Las razones de este hecho son diversas. Por un lado, el modelo de emancipación continental o corporativista comparte con el modelo socialdemocrático el reconocimiento del derecho de la juventud a poder independizarse, pero difiere sustancialmente de este en el modo en que el sector público apoya este proceso. El Estado desempeña un papel mucho menor, lo que genera una mayor dependencia de la juventud a la ayuda familiar y a su inserción laboral. Por otro lado, el periodo de estudios acostumbra a ser largo, muy a menudo implica la emancipación residencial si se dispone del apoyo económico familiar necesario y ello suele ser determinante para la calidad del primer empleo. Esta disociación entre emancipación residencial y emancipación económica se ha venido a denominar como trayectorias independientes de la juventud (Chanvril et al., 2009) y es un fenómeno característico del modelo corporativista.

En cuanto a su sistema de vivienda, la heterogeneidad es su característica principal. Por ejemplo, el tamaño del parque de alquiler social varía formidablemente de un país a otro (Laino y Pittini, 2011), puesto que en Holanda llega al 32\% y apenas al 2\% en Luxemburgo. Por consiguiente, algunos países responden al modelo dual de Kemeny y otros, al unitario. Esta disparidad de situaciones también se repite en materia de ayudas para el pago del domicilio, así como en el gasto público asociado a las mismas, y es muy probable que sea una de las principales razones que expliquen las diferencias existentes en las tasas de emancipación entre países corporativistas (gráfico 1).

\subsection{El modelo de emancipación liberal}

El modelo de emancipación liberal se caracteriza por un abandono del hogar de los progenitores a edades relativamente tempranas, similares a las de los 
países corporativistas (gráfico 1), lo que propicia una rápida formación de familias y la maternidad, pero también conlleva un mayor riesgo de pobreza. Este patrón de emancipación es posible gracias, por un lado, a un mercado laboral que, históricamente, ha combinado una elevada flexibilidad con un bajo desempleo juvenil (Walther, 2006), y, por otro, a una política de vivienda que favorece dicha transición residencial, ya sea mediante ayudas directas al pago del alquiler, ya sea en forma de vivienda social. Incluso tras años de progresiva privatización del mismo, el tamaño del parque de vivienda social es significativo en Irlanda y el Reino Unido (Laino y Pittini, 2011), pero, a pesar de ello, su sistema de vivienda, según la clasificación de Kemeny, se considera dual, dado que se dirige casi de forma exclusiva a las personas en situación de riesgo de exclusión social (Czischke y Pittini, 2007; Laino y Pittini, 2011).

Asimismo, el sistema de ayudas para el pago de la vivienda es amplio, en particular en el Reino Unido, pero no universal, ya que también se dirige solo a los grupos más vulnerables. Hay que tener en cuenta que el modelo liberal genera una fuerte estratificación, desigualdad y exclusión social, y, por consiguiente, un elevado porcentaje de la población depende de las ayudas públicas para poder acceder a una vivienda adecuada.

Dentro del modelo liberal europeo, es obligado hablar de los valores católicos imperantes en Irlanda. Su influencia se manifiesta en sus menores tasas de emancipación residencial (gráfico 1) y en una mayor proporción de jóvenes que abandonan el hogar de sus progenitores para casarse y formar una familia. Ello explica que algunos autores sitúen a Irlanda más cerca del modelo mediterráneo de emancipación que del propiamente liberal (Berthoud y Iacovou, 2004; Iacovou, 2004).

\subsection{El modelo de emancipación mediterráneo}

En el modelo mediterráneo (o rudimentario), el papel de la familia es decisivo. La permanencia en el hogar de los progenitores suele ser muy prolongada, y es muy común que, con el ahorro previo que las personas jóvenes pueden realizar durante este periodo, y usualmente con la ayuda de estos, la emancipación implique la compra de la vivienda (Allen et al., 2004; Emmanuel, 2013).

Otro factor que retrasa la emancipación de la juventud en este modelo es el riesgo de pobreza asociado al mismo. La debilidad del estado de bienestar mediterráneo genera una fuerte dependencia de las personas jóvenes respecto al apoyo de sus progenitores, por lo que la temprana emancipación de los jóvenes procedentes de hogares en riesgo de pobreza multiplica los riesgos de exclusión social. Además, convivir con los progenitores es también una garantía de protección socioeconómica intrafamiliar, no solo por el apoyo de padres a hijos, sino también en sentido inverso (Cantó y Mercader, 2001a, 2001b; Parisi, 2008; Ayllón, 2009).

Pero el retraso de la emancipación residencial no responde exclusivamente a motivos económicos. La prolongación del periodo de estudios (la incorporación al mercado laboral acostumbra a producirse después de estos) también ha contri- 
buido a ello, así como la incertidumbre que sufre la juventud respecto al trabajo remunerado, fruto de la fuerte precariedad y liberalización del mismo, así como la cada vez más extendida opción por mantener un nivel alto de consumo a cambio de postergar la emancipación (las elecciones individuales antes mencionadas).

Por su parte, el sistema de vivienda de los países mediterráneos tampoco facilita la transición residencial de la juventud (Aassve et al., 2002; Iacovou, 2002; Allen et al., 2004; Emmanuel, 2013). El alcance de la política practicada en ese sentido es muy limitado y, por lo general, solo se orienta a fomentar el acceso al domicilio en propiedad. Como resultado, en la mayoría de países mediterráneos, el parque de alquiler privado es muy reducido, y el de alquiler social, ínfimo (Allen et al., 2004; Laino y Pittini, 2011), lo que convierte estos sistemas en extremadamente duales. Además, ante la ausencia de un método de ayudas para el pago de los hogares en régimen de alquiler mínimamente desarrollado, las posibilidades de las personas jóvenes en el mercado de la vivienda acaban dependiendo exclusivamente de sus ingresos y de la capacidad de apoyo familiar (Walther, 2006; Anxo et al., 2010).

\subsection{El modelo de emancipación postsocialista o de transición}

El análisis de la emancipación en el modelo de transición (o también denominado postcomunista o postsocialista) plantea mayores dificultades. Por un lado, el debate sobre la existencia de un único modelo de estado de bienestar propiamente de transición o de varios aún hoy está vigente en el mundo académico. Rys (2001) afirma que no existe una convergencia común entre ellos. Ferreira y Figueiredo (2005) sostienen que algunos de estos países podrían incluirse en alguna de las tipologías existentes, mientras otros forman un grupo propio. Keune (2006) considera que son excesivamente jóvenes y aún es pronto para definir su tipo de estado de bienestar. Según Fenger (2007), pueden dividirse en tres grupos:

1. Los países de la antigua Unión Soviética (Letonia, Estonia, Lituania, Rusia, Ucrania y Bielorrusia).

2. La denominada tipología europea postcomunista, formada por países del centro y del este de Europa (Bulgaria, Croacia, República Checa, Hungría, Polonia y Eslovaquia).

3. Un grupo de países en desarrollo formado por Rumania, Moldavia y Georgia.

Algunos autores como Stephens et al. (2010) dividen estos países en dos grupos:

1. Los países del modelo conservador postcomunista, que disponen de un cierto grado de protección laboral.

2. El modelo liberal postsocialista, caracterizado por un mercado laboral flexible.

Otros, como Fuchs (2008), simplemente abogan por la inexistencia de un nuevo modelo de estado de bienestar postsocialista. 
Por otro lado, el modelo de emancipación en estos países es, sin lugar a dudas, el menos estudiado de todos ellos y, por consiguiente, la literatura existente sobre el mismo es mucho más limitada. No obstante, según Roberts $(2009,2010)$, a pesar de las diferencias existentes entre los países del antiguo bloque soviético en materia de juventud, hay unos rasgos comunes que configuran un modelo propio de emancipación. Este se caracteriza por unas grandes dificultades de la juventud para abandonar el hogar parental, una prolongada dependencia de la familia y un elevado porcentaje de jóvenes que viven con sus progenitores, así como de hogares multigeneracionales. Además, muchas personas jóvenes con trabajo no pueden afrontar el pago de una vivienda en alquiler o acceder a un crédito hipotecario, por lo que su emancipación queda a menudo condicionada a la capacidad de ayuda de la familia, ya sea en forma de apoyo económico, herencia de la vivienda familiar o cesión de la misma. Estas prácticas, que ya eran habituales en el periodo comunista, se han acentuado con el nuevo régimen, lo cual ha generado una fuerte fractura social entre aquella juventud cuyas familias disponen de recursos para ayudar a sus procesos de emancipación y aquellas que no pueden. En pocas palabras, el estatus del hogar es el factor más determinante en los procesos de emancipación, lo que fomenta la división social entre grupos.

Para poder entender las dificultades de emancipación de la juventud en estos países es imprescindible revisar la evolución que han sufrido sus sistemas de vivienda. En el anterior modelo de vivienda socialista, el Estado ejercía un amplio control del sector residencial. Los mecanismos de mercado estaban completamente subordinados a la planificación oficial, lo cual mantenía el precio de la vivienda artificialmente bajo (Hegedüs y Tosics, 1996). Sin embargo, este control cuasi absoluto del sector por parte del Estado no se tradujo en unos niveles de producción de vivienda acordes con las necesidades vigentes, de modo que el déficit de vivienda fue un problema permanente durante el periodo comunista. Esto favoreció el desarrollo de una economía residencial informal al margen de la oficial, en donde se celebraban transacciones de compraventa, contratos privados de alquiler y subarriendos (Hegedüs, 2008).

Con el fin del comunismo y el posterior cambio hacia una economía de mercado, los sistemas de vivienda de los países del este de Europa (el East-European Housing Model, o EEHM en la literatura anglosajona) sufrieron una profunda transformación. Bajo la influencia del Banco Mundial y el Fondo Monetario Internacional, la reforma económica se centró, por un lado, en limitar al máximo el papel del Estado, incluso en materia de políticas sociales, y, por otro, en una abierta defensa del mercado libre. Además, los países que se incorporaron a la Unión Europea sobre la base de los objetivos del Tratado de Lisboa, tuvieron que priorizar aún más la competitividad y la creación de empleo por encima del gasto social, lo que incrementó sus ya elevados niveles de exclusión social, desigualdad y pobreza.

De este modo, en aplicación de los principios del Consenso de Washington, en casi todos los países, el cambio de régimen fue acompañado de una privatización masiva del enorme parque de vivienda social construido en el 
periodo comunista, y la propiedad pasó a ser el régimen de tenencia ampliamente mayoritario (Laino y Pittini, 2011). Solamente en Polonia y Chequia, en lugar de llevarse a cabo una venta masiva del parque social a sus inquilinos de forma inmediata tras el cambio de régimen, la privatización ha sido un lento proceso (aún en desarrollo) impulsado por la transferencia de dicho parque a los gobiernos locales y favorecido por las sucesivas reformas legislativas sobre su gestión patrimonial.

En la actualidad, el gasto público en política de vivienda sigue siendo muy bajo, lo que explica tanto la escasa oferta de vivienda social como la debilidad (o ausencia) de un sistema de ayudas para el pago de la vivienda mínimamente desarrollado. Es más, en aquellos países que disponen de algún tipo de subvención, por lo general, esta, o bien tiene por objeto ayudar a cubrir los gastos de los servicios de la vivienda, como por ejemplo, la electricidad, el agua o la recogida de basuras (en contrapartida a la liberalización y privatización de dichos servicios) o bien se dirige a facilitar el acceso a una vivienda en propiedad, sobre todo entre las clases medias (Hegedüs y Teller, 2005).

En el plano competencial, la llegada de la democracia supuso una paulatina descentralización de las competencias en materia de vivienda del gobierno central hacia los gobiernos locales. En la actualidad, los municipios se han convertido en los principales actores públicos en este campo en la mayoría de países. Estos se encargan del mantenimiento, la gestión y la promoción de vivienda social en su territorio, deciden sobre su privatización, las inversiones a realizar y el sistema de adjudicación y los niveles de renta de los adjudicatarios (Laino y Pittini, 2011). Pero esta transferencia de competencias no ha ido acompañada de los correspondientes recursos económicos, lo que ha contribuido a la privatización del escaso parque de vivienda social restante y al mantenimiento de un muy bajo nivel de construcción de nueva vivienda social (Hegedüs et al., 2013).

Otro problema característico de los sistemas de viviendas postsocialistas es la baja calidad de sus parques residenciales. La vivienda promovida durante el periodo comunista fue de muy baja calidad constructiva, el mantenimiento ha sido ínfimo, tanto durante el periodo comunista como después de este, y los programas de rehabilitación, muy limitados. Además, en el segmento del parque más deteriorado se concentra la población socioeconómicamente vulnerable y, por consiguiente, sin capacidad de gasto para mejorar su vivienda (Hegedüs y Tosics, 1996; Hegedüs y Teller, 2004; Domanski, 2008; Mandic y Cirman, 2012).

A causa de todos estos factores, en particular de la debilidad de su política de vivienda, los niveles de exclusión residencial y sinhogarismo son elevados en estos países. Los grupos más afectados son, sobre todo, las personas que no pudieron acceder a la propiedad de una vivienda social tras el cambio de régimen y que no disponen de recursos suficientes (Fitzpatrick y Stephens, 2007a, 2007b), así como las que se han incorporado al mercado residencial tras la privatización del parque público, como, por ejemplo, las personas jóvenes, como ponen de relieve sus bajas tasas de emancipación (gráfico 1). Por ello, 
Gráfico 1. Tasa de emancipación de las personas de 18 a 34 años. Europa, media del periodo 2006-2011

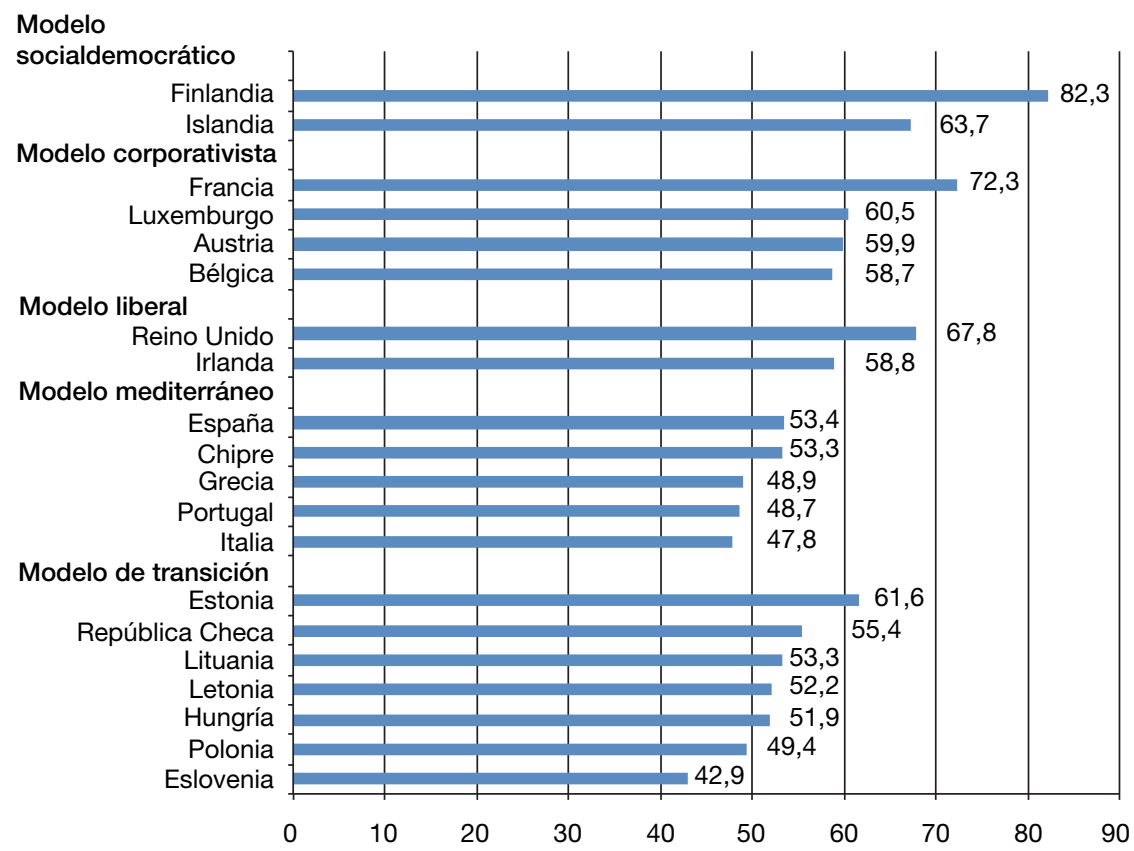

Fuente: elaboración propia a partir de EUROSTAT, European Survey on Income and Living Conditions (EU SILC).

al igual que en el modelo mediterráneo, la familia desempeña un papel clave como elemento de protección de sus miembros que va más allá de los procesos de emancipación.

2. Estudio comparado de la relación entre política de vivienda y tasas de emancipación residencial de la juventud europea

\subsection{Aspectos metodológicos}

La revisión de la literatura existente sobre los procesos de emancipación según el tipo de estado de bienestar y las características de sus sistemas de vivienda sugiere la existencia de una fuerte relación entre tasas de emancipación y grado de desarrollo de la política de vivienda en cada sistema. Para confirmar el alcance de dicha asociación, hemos realizado un estudio cuantitativo a partir de los resultados de la encuesta EU SILC (European Union Statistics of Income and Life Conditions) correspondientes al periodo 2006-2011. La ausencia de información estadística relevante y comparable sobre el alcance de la política de vivienda entre las personas jóvenes en Europa, incluyendo los nuevos estados 
miembros de la Unión Europea del este de Europa ha sido un problema insoslayable para este tipo de trabajos hasta la aparición de la encuesta EU SILC. A partir de 2006, la $E U$ SILC se implementó en la mayoría de países europeos, por lo que, sin lugar a dudas, constituye una fuente de información única y excepcional con la que poder cubrir el vacío existente en los estudios europeos comparados de esta naturaleza.

El método empleado para medir la asociación entre variables ha sido el de la regresión lineal. Al respecto, es importante subrayar que el estudio carece de control de otros factores estructurales (o variables independientes) que también inciden en las tasas nacionales de emancipación, como, por ejemplo, la integración de la juventud en el mercado laboral o el nivel de desarrollo económico de cada país, por lo que el presente análisis de correlaciones no puede interpretarse de ningún modo como una prueba de la existencia de relación causal entre las variables de política de vivienda y las tasas de emancipación.

En cuanto a las variables de política de vivienda, hay que tener en cuenta que los instrumentos dirigidos a resolver los problemas de accesibilidad económica de la demanda pueden clasificarse en dos grandes grupos según el destinatario:

1. Las ayudas directas a las personas (o housing benefits), en forma de prestaciones económicas o similares, para el pago del alquiler o la compra de la vivienda

2. Las ayudas comúnmente denominadas a la piedra a promotores y constructores, para que construyan vivienda social.

Si bien existen otros instrumentos, como, por ejemplo, las políticas de movilización del parque desocupado, de mediación entre propietarios e inquilinos, o de determinación legal del coste del alquiler según la capacidad económica de los inquilinos, los dos instrumentos mencionados son, de forma abrumadora, los más importantes en Europa, tanto en términos de recursos públicos destinados a los mismos como en porcentaje de población beneficiaria de estos.

Respecto al primer grupo, la EU SILC nos permite conocer el alcance de los housing benefits desde tres variables:

1. El porcentaje de personas que reciben dichas ayudas.

2. La proporción que representan respecto al total de costes residenciales.

3. Su importe medio anual.

Respecto al segundo grupo, la $E U$ SILC también recoge información sobre el porcentaje de población que vive en una vivienda de alquiler cuyo precio es inferior al de mercado. No obstante, hay que tener presente que tal definición no se ajusta de un modo exacto al concepto de vivienda social comúnmente aceptado. Por lo general, el término vivienda social se refiere a aquella que es de alquiler, económicamente asequible y cuya provisión no se realiza dentro 
de los mecanismos del mercado, sino que es el resultado de procesos impulsados directa o indirectamente por el sector público, con el fin de atender a las necesidades residenciales de la población con problemas de accesibilidad económica a la vivienda (Laino y Pittini, 2011), mientras que la definición empleada sería más amplia, puesto que también englobaría aquellas viviendas de renta antigua cuyo precio es inferior al de mercado. Sin embargo, dado el reducido peso de este tipo de alquiler en el total del parque, muy en particular entre las personas jóvenes emancipadas, a lo largo del estudio consideraremos como vivienda social aquella de alquiler que simplemente tiene un precio inferior a la de mercado.

Para analizar de forma global el alcance de la política de vivienda entre la juventud de cada país, hemos construido un indicador compuesto formado por el sumatorio de dos variables:

1. El porcentaje de personas jóvenes emancipadas de cada país que viven en una vivienda social en cada bienio dividido por la desviación estándar de los $N$ casos

2. Más el porcentaje que representan las ayudas para el pago de la vivienda entre la juventud emancipada respecto al total de costes de la vivienda, también dividido por la desviación estándar de esta variable, y todo ello dividido por la desviación estándar del indicador (véase cuadro 1).

Para examinar la situación económica de las personas jóvenes en el mercado y su asociación con el alcance de la política de vivienda, también a partir de la $E U S I L C$ se han construido dos indicadores de accesibilidad económica: el denominado esfuerzo económico y la tasa de sobreesfuerzo económico destinado a la vivienda. El primero expresa la relación entre el coste de la vivienda respecto a los ingresos disponibles del hogar. En el cómputo del coste de la vivienda, se contabilizan la totalidad de los servicios e impuestos (agua, electricidad, alcantarillado, recogida de basuras, seguro, impuesto de bienes inmuebles y otros impuestos municipales) y el alquiler o la cuota hipotecaria sin la parte correspondiente a amortización del crédito hipotecario, dado que la metodología de EUROSTAT considera este gasto ligado a un bien de consumo de naturaleza duradera. El segundo indicador se refiere al porcentaje de población en hogares cuyo esfuerzo económico es superior al $40 \%$ de sus ingresos.

Cuadro 1. Expresión matemática del indicador compuesto de grado de desarrollo de la política de vivienda para las personas de 18 a 34 años emancipadas.

Indicador = [(var1 / SD var1) + (var2 / SD var2) $]$ / SD Indicador, siendo:

$\mathrm{SD}=$ desviación estándar de la variable correspondiente.

Var1: porcentaje de personas jóvenes emancipadas que habitan una vivienda social.

Var2: porcentaje que representan las ayudas para el pago de la vivienda entre la juventud emancipada respecto al total de costes que se deben afrontar.

Fuente: elaboración propia. 
Por su parte, en consonancia con el prolongamiento de los procesos de transición a la vida adulta y su trasposición a las políticas públicas relacionadas (la mayoría de programas dirigidos a facilitar la emancipación tienen como grupo destinatario las personas de entre 18 y 30 o hasta los 34 años), se han considerado como personas jóvenes emancipadas aquellas de entre 18 y 34 años que no viven con sus padres o madres ni con alguna otra persona que considere como tales.

Por último, cabe señalar además que:

1. Todos los resultados se han agrupado por bienios para reducir su error muestral.

2. Del total de países europeos cubiertos por la EU SILC a lo largo del periodo 2006-2011, se han excluido del estudio Dinamarca, Noruega, Suecia y Holanda, por la incapacidad de la encuesta para recoger información sobre su parque de alquiler social; además de Alemania y Eslovaquia, por idénticos motivos en materia de ayudas para el pago de la vivienda.

3. Al igual que el grueso de investigación contextual en este campo, más allá de los resultados a nivel nacional, estos se han puesto en relación con los diferentes modelos de estado de bienestar a partir de la clasificación de EspingAndersen (1990), ampliada con el modelo mediterráneo (o rudimentario) (Leibfried, 1992; Ferrera, 1996) y el de transición (Kornai, 1992).

\subsection{Vivienda social y emancipación residencial}

Las grandes diferencias en el peso de la vivienda social entre los diferentes países europeos se reproducen de un modo similar al comparar el porcentaje de personas jóvenes emancipadas que viven en una vivienda social (anexo 1, tabla 3). Tomando los mismos intervalos de tamaño del parque social que emplea el Observatorio Europeo de Vivienda Social para clasificar los sistemas de vivienda europeos (Czischke y Pittini, 2007: 16), pero aplicados al peso de la vivienda social entre las personas jóvenes emancipadas, podemos clasificar los veinte países analizados en cuatro grupos (tabla 1). Solo en Finlandia y Francia el peso de la vivienda social entre las personas jóvenes emancipadas es superior al 20\% (primer grupo); en Austria, Reino Unido, Islandia, Irlanda y Chequia, se sitúa entre el 10\% y el 20\% (segundo grupo); en Bélgica, Estonia, Letonia y Hungría, oscila entre el 5\% y el 10\% (tercer grupo), y, por último, en Luxemburgo, en la totalidad de países mediterráneos y en el resto de los del modelo de transición, la vivienda social desempeña un papel residual como instrumento para facilitar la emancipación residencial de la juventud habida cuenta de que ni siquiera supone una opción para el 5\% de las personas emancipadas de entre 18 y 34 años (cuarto grupo).

Resulta interesante constatar que en Austria y Francia, los dos países corporativistas con más vivienda social, y en los socialdemocráticos (Islandia y Finlandia), el porcentaje de personas jóvenes emancipadas en el parque social es mayor que el del conjunto de la población (anexo 1, tabla 3), de lo cual se deduce que, en estos: 
Tabla 1. Clasificación de los sistemas europeos de vivienda social según el porcentaje de personas emancipadas de 18 a 34 años que viven en una vivienda social (Europa, 2006-2011)

\begin{tabular}{|c|c|c|c|c|c|c|c|c|c|}
\hline \multirow[b]{2}{*}{ Grupo } & \multirow[b]{2}{*}{$\begin{array}{l}\text { Nivel de } \\
\text { desarrollo } \\
\text { del sistema de } \\
\text { vivienda social } \\
\text { para la juventud }\end{array}$} & \multirow[b]{2}{*}{ Países } & \multicolumn{5}{|c|}{$\begin{array}{l}\text { Modelo de estado } \\
\text { de bienestar }\end{array}$} & \multirow[b]{2}{*}{$\begin{array}{l}\text { Porcentaje } \\
\text { de personas } \\
\text { jóvenes } \\
\text { emancipadas } \\
\text { en una vivienda } \\
\text { social }\end{array}$} & \multirow[b]{2}{*}{$\begin{array}{l}\text { Porcentaje } \\
\text { de población } \\
\text { en una } \\
\text { vivienda } \\
\text { social }\end{array}$} \\
\hline & & & 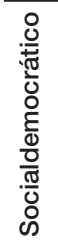 & 矛 & 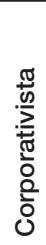 & 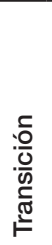 & 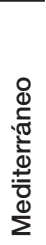 & & \\
\hline \multirow[t]{7}{*}{1} & Muy elevado & Francia & & & $\square$ & & & $>20 \%$ & $14 \% \rightarrow 19 \%$ \\
\hline & & Finlandia & $\square$ & & & & & & \\
\hline & Elevado & Islandia & $\square$ & & & & & $10 \% \rightarrow 20 \%$ & $6 \% \rightarrow 17 \%$ \\
\hline & & Austria & & & $\square$ & & & & \\
\hline & & Reino Unido & & $\square$ & & & & & \\
\hline & & Irlanda & & $\square$ & & & & & \\
\hline & & Rep. Checa & & & & $\square$ & & & \\
\hline \multirow[t]{4}{*}{2} & Débil & Bélgica & & & $\square$ & & & $5 \% \rightarrow 10 \%$ & $2 \% \rightarrow 10 \%$ \\
\hline & & Estonia & & & & $\square$ & & & \\
\hline & & Letonia & & & & $\square$ & & & \\
\hline & & Hungría & & & & $\square$ & & & \\
\hline \multirow[t]{9}{*}{3} & Residual & Luxemburgo & & & $\square$ & & & $<5 \%$ & $\leq 5 \%$ \\
\hline & & Eslovenia & & & & $\square$ & & & \\
\hline & & Polonia & & & & $\square$ & & & \\
\hline & & Lituania & & & & $\square$ & & & \\
\hline & & Chipre & & & & & $\square$ & & \\
\hline & & Portugal & & & & & $\square$ & & \\
\hline & & España & & & & & $\square$ & & \\
\hline & & Italia & & & & & $\square$ & & \\
\hline & & Grecia & & & & & $\square$ & & \\
\hline
\end{tabular}

1. Para la clasificación de Irlanda, Luxemburgo, Italia, Portugal y la República Checa, dada su evolución a lo largo del periodo 2006-2011, se han tomado los datos correspondientes al bienio 2010-2011.

Fuente: elaboración propia a partir de EUROSTAT, European Survey on Income and Living Conditions (EU SILC).

1. Existe disponibilidad de vivienda social para este colectivo, ya sea a partir de nuevas promociones o bien a consecuencia de una rotación significativa en dicho parque social

2. La juventud es efectivamente un grupo prioritario en los procesos de adjudicación.

En cambio, en el modelo liberal (Irlanda y Reino Unido), a pesar de que, en teoría, las personas jóvenes son también un grupo prioritario (Whitehead y Scanlon, 2007; Pittini y Baloup, 2012), el peso de la vivienda social entre la juventud emancipada es similar al del conjunto de la población. 
Gráfico 2. Correlación entre las tasas de emancipación de la población de 18 a 34 años y el porcentaje de personas emancipadas de 18 a 34 años que viven en el parque de alquiler social (Europa, bienios 2006-2007, 2008-2009 y 2010-2011)

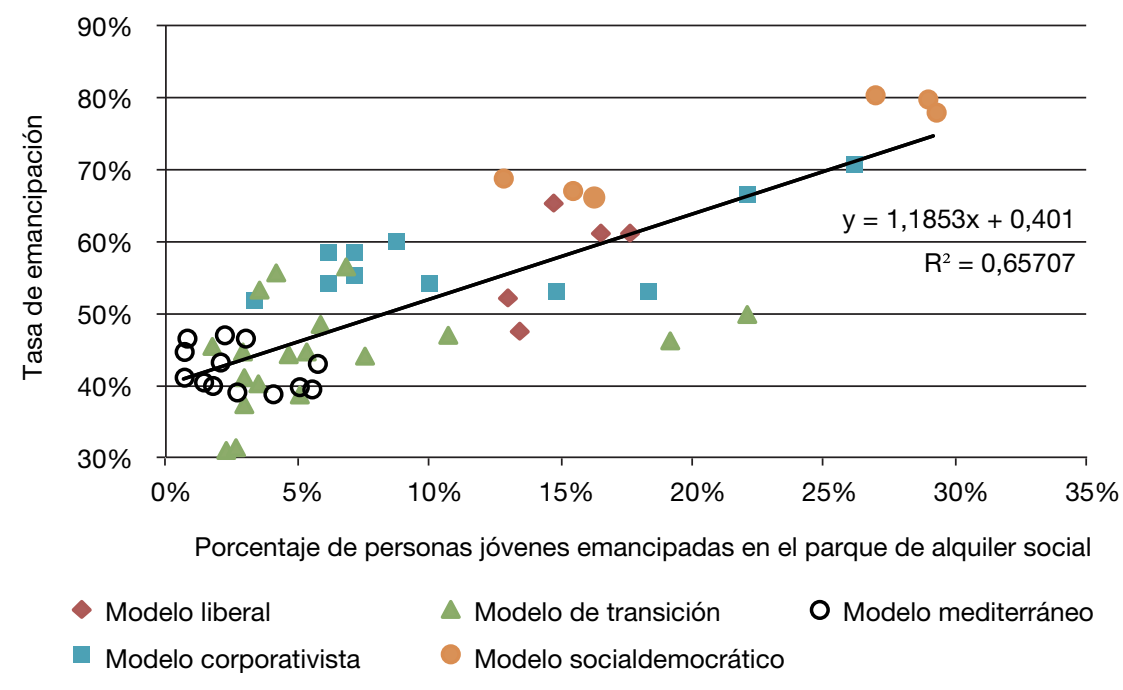

Fuente: elaboración propia a partir de EUROSTAT, European Survey on Income and Living Conditions (EU SILC).

Respecto a la asociación entre el porcentaje de personas jóvenes emancipadas en una vivienda social y las tasas nacionales de emancipación, la regresión lineal bivariable (de $N=60$, dado que la comparación se realiza por cada bienio de forma separada) confirma la existencia de una considerable correlación de signo positivo entre ambas variables (coeficiente de determinación $R^{2}=0,6571$, coeficiente de correlación de Pearson $=0,81$ ) (gráfico 2). No obstante, cada modelo de estado de bienestar sigue una pauta determinada. Los países mediterráneos y, en menor medida, los del modelo de transición (con la excepción de Chequia, debido al lento proceso de privatización aún inconcluso) son relativamente homogéneos y tienden a acumularse en el extremo inferior de la recta de regresión, debido a sus bajas tasas de emancipación y a su escaso parque social; los liberales ocupan la zona central; los del modelo socialdemocrático se sitúan en la zona superior, siempre por encima de la recta de regresión a causa de sus elevadas tasas de emancipación, y, en cambio, los países corporativistas, dada su heterogeneidad, se distribuyen a lo largo de toda la recta de regresión. Gráfico 2.

\subsection{Las ayudas para el pago de los costes de la vivienda}

El nivel de desarrollo del sistema de ayudas públicas para el pago de la vivienda también muestra diferencias notables entre países (anexo 1, tabla 4). El indi- 
cador más representativo de este instrumento es el porcentaje que representan estas ayudas respecto a los costes de la vivienda de la totalidad de las personas jóvenes emancipadas, ya que refleja, por un lado, la proporción de beneficiarios sobre el total del grupo de edad considerado y, por otro, el importe de dicha ayuda en relación con los costes totales de la vivienda. Como anteriormente, a partir de dicho indicador, podemos clasificar los países en cuatro grupos (tabla 2).

En el primer grupo (Islandia, Finlandia y Francia), este sistema de ayudas es muy extenso, puesto que cubren más del $12 \%$ del total de costes residenciales de la juventud emancipada. Lógicamente, tiene un carácter universal, tal como muestra el elevado número de jóvenes receptores y constituye una ayuda esencial para mejorar la accesibilidad económica de las personas beneficiarias dado su importe medio (tabla 2). Asimismo, en comparación con el conjunto de la población, la juventud emancipada de estos países, fundamentalmente jóvenes en alquiler, se beneficia en mayor medida de las mismas (anexo 1, tabla 4) que el conjunto de la población.

Irlanda y el Reino Unido son los dos únicos países cuyo porcentaje de ayudas se sitúa entre el 6\% y el $8 \%$ de los costes, por lo que el modelo liberal constituye el segundo grupo. En este, los denominados housing benefits tienen un grado de desarrollo, aunque inferior, significativo, se orientan al alquiler y no son universales, sino que se dirigen al segmento de población socioeconómicamente más desfavorecida (means-tested), con independencia de la edad. En concreto, entre un $11 \%$ y un $18 \%$ de la población joven emancipada recibe este tipo de ayudas, un porcentaje similar al del conjunto de la población. Otra particularidad del modelo liberal de ayudas para el pago de la vivienda es su elevado importe medio anual, especialmente en el Reino Unido, lo que explicaría el considerable gasto público en este instrumento (Laino y Pittini, 2011).

Austria, Luxemburgo, Chipre y Portugal constituyen el tercer grupo. Su principal rasgo en común es el débil desarrollo de este instrumento: estas ayudas apenas representan entre el $2 \%$ y el $4 \%$ del total de costes residenciales de la juventud emancipada, y solo benefician a un porcentaje situado entre el 5\% y el $15 \%$ de dicho colectivo.

Por último, Bélgica, el resto de países mediterráneos y la totalidad de los del modelo de transición (grupo 4) se caracterizan por la extrema debilidad de sus políticas de ayuda al pago de los costes residenciales de las personas jóvenes emancipadas. Este es tan residual que ni siquiera representa el $2 \%$ del total, lo cual, obviamente, implica un porcentaje muy bajo de población receptora y de importes mínimos. Además, en coherencia con el elevado peso de la vivienda en propiedad en estos países, estas ayudas no solo tienen por objeto el pago del alquiler de la población más desfavorecida, sino que frecuentemente están encaminadas a facilitar el acceso de las clases medias a la propiedad y, en otros casos, a sufragar parte de los servicios de la vivienda.

En cuanto a la relación entre las tasas de emancipación y el porcentaje que representan las ayudas para el pago de la vivienda respecto al total de costes de esta entre las personas jóvenes emancipadas $(N=60)$, la regresión también 
Tabla 2. Clasificación de los sistemas europeos de ayudas para el pago de los costes de la vivienda de las personas emancipadas de 18 a 34 años (Europa, 2006-2011)

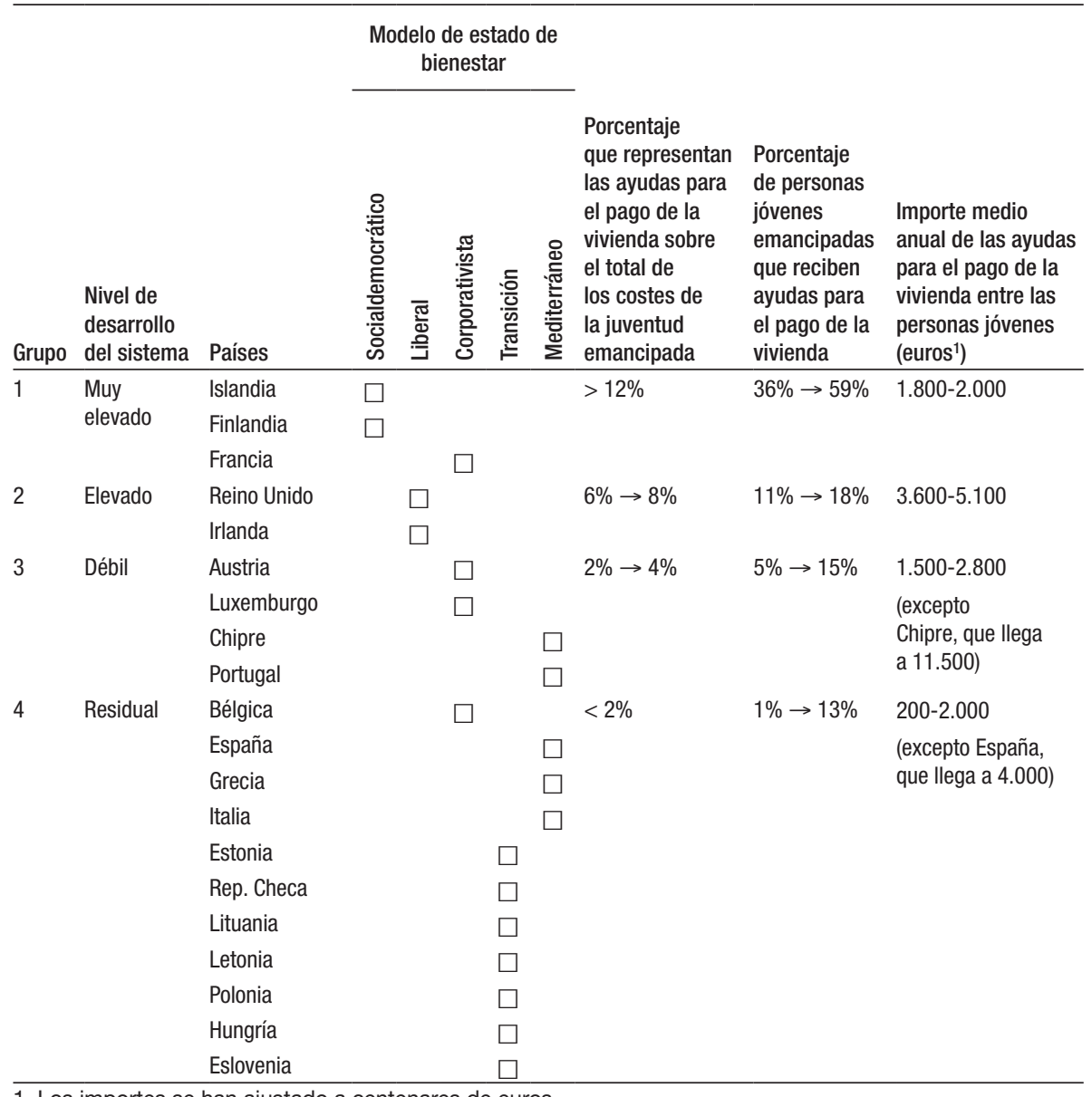

1. Los importes se han ajustado a centenares de euros.

Fuente: elaboración propia a partir de EUROSTAT, European Survey on Income and Living Conditions (EU SILC).

muestra una correlación positiva entre ambas variables casi coincidente con los resultados anteriores relativos a la vivienda social (coeficiente de determinación $R^{2}=0,6667$, coeficiente de correlación de Pearson de 0,82) (gráfico 3). Tal correspondencia responde en gran medida al hecho de que ambas variables de política de vivienda están también fuertemente correlacionadas entre sí $\left(R^{2}\right.$ = 0,6196, coeficiente de correlación de Pearson de 0,79). Es decir, los países con mayor proporción de jóvenes emancipados en el parque social también acostumbran a tener sistemas más robustos de ayudas para el pago de la vivienda de las personas jóvenes, y a la inversa. Los únicos países que no siguen dicha pauta son cinco. En Austria y Chequia, la política de vivienda para los 
Gráfico 3. Correlación entre las tasas de emancipación de la población de 18 a 34 años y el porcentaje que representan las ayudas públicas para el pago de los costes de la vivienda de las personas emancipadas de 18 a 34 años respecto al total de costes residenciales de dicho grupo (Europa, bienios 2006-2007, 2008-2009 y 2010-2011)

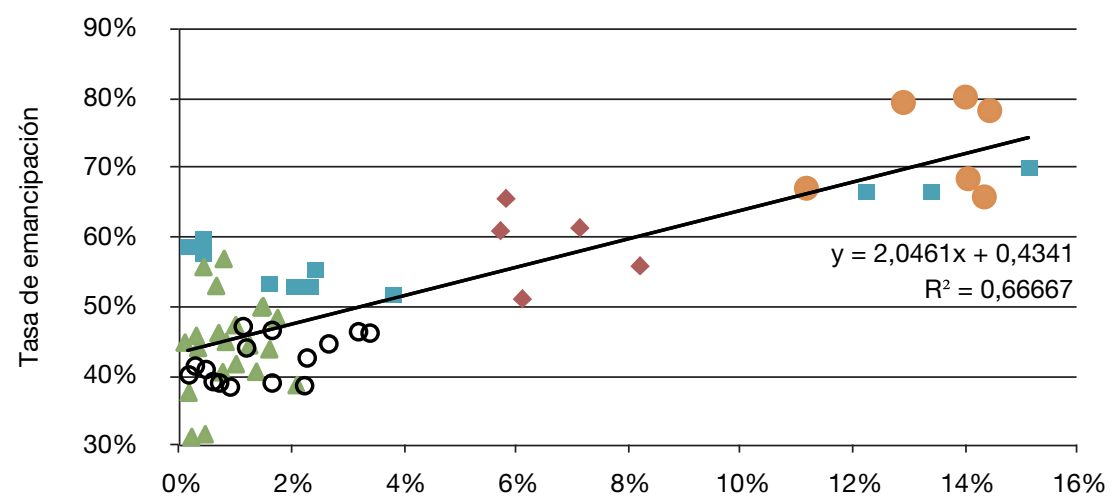

Porcentaje que representan las ayudas al pago de la vivienda respecto el total de costes de ésta entre las personas jóvenes emancipadas (reciban o no dichas ayudas)

- Modelo liberal

Modelo corporativista
Modelo de transición

Modelo socialdemocrático

Fuente: elaboración propia a partir de EUROSTAT, European Survey on Income and Living Conditions (EU SILC).

jóvenes está centrada casi exclusivamente en la vivienda social y. en cambio, en Portugal, Luxemburgo y Chipre, el principal instrumento lo constituyen las ayudas para pagar el domicilio.

Asimismo, como puede advertirse en el gráfico 3, cuando las ayudas para el pago de la vivienda son muy reducidas en términos de porcentaje sobre el total de costes residenciales de las personas jóvenes emancipadas, disminuye la correlación entre ambas variables. De hecho, existe un límite por debajo del cual no hay relación alguna entre ambas variables: el $2 \%$ del total de costes de la vivienda de las personas jóvenes. Cuando el sistema de ayudas supera dicho $2 \%$, la correlación es muy fuerte $(N=26$, coeficiente de determinación $R^{2}=0,7573$, coeficiente de correlación de Pearson de 0,87$)$ y, por el contrario, es nula por debajo de dicho porcentaje $(N=34$, coeficiente de determinación $R^{2}=0,0041$, coeficiente de correlación de Pearson de 0,06).

\subsection{Una visión global de la politica de vivienda europea desde la emancipación residencial de las personas jóvenes}

El indicador compuesto construido a partir de las variables anteriores nos permite obtener una visión más amplia del diferente grado de desarrollo de la política de vivienda para la juventud. Si realizamos la media de dicho indica- 
Gráfico 4. Indicador compuesto del grado de desarrollo de la política de vivienda para las personas de 18 a 34 años emancipadas (Europa, media de los bienios 2006-2007, 20082009 y 2010-2011)

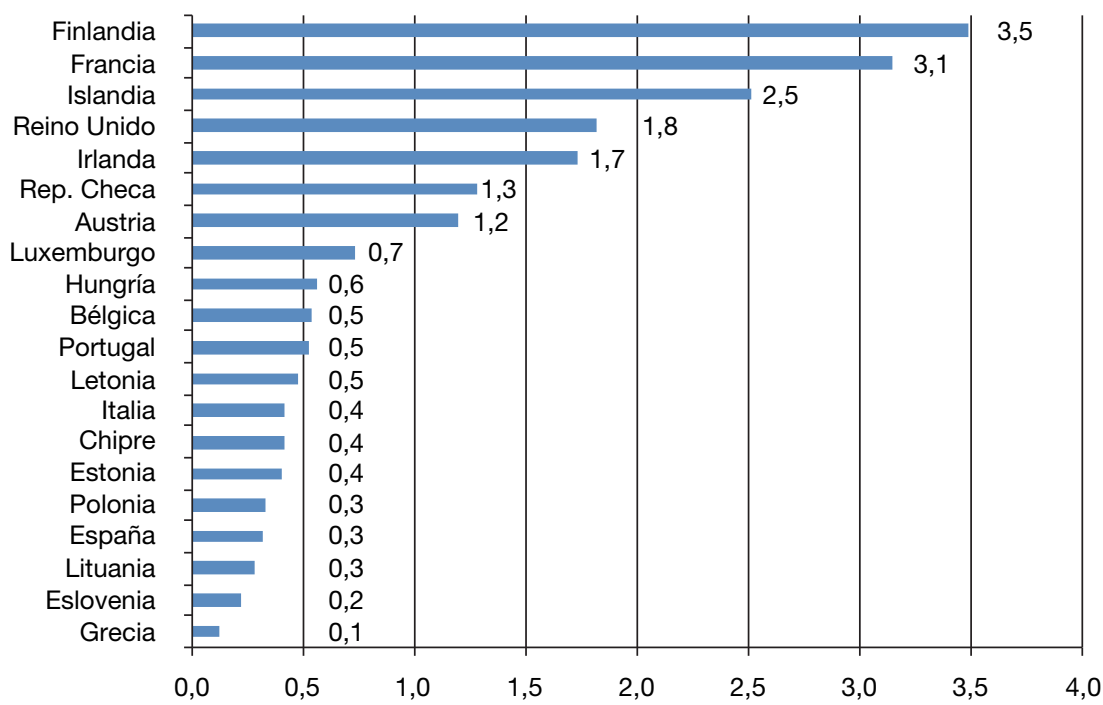

Fuente: elaboración propia a partir de EUROSTAT, European Survey on Income and Living Conditions (EU SILC).

dor de los tres bienios considerados (gráfico 4), como cabía prever, Finlandia, Francia e Islandia destacan por encima del resto de países, por el vasto desarrollo de su política de vivienda para la juventud (Indicador $>2,5$ ), seguidos a cierta distancia por Irlanda y el Reino Unido, con unos valores muy similares $(1,7-1,8)$, y entre los restantes países, únicamente en la República Checa $(1,3)$ y Austria $(1,2)$ este indicador alcanza valores superiores a la unidad.

Lógicamente, estos resultados reproducen la relación entre modelos de estado de bienestar y alcance de la política de vivienda entre las personas jóvenes vista anteriormente. Los países socialdemocráticos y los del modelo liberal logran, por este orden, los mejores resultados; por el contrario, los países mediterráneos y de transición obtienen los valores más bajos, y, de nuevo, los del modelo corporativista no siguen una pauta homogénea. Mientras Francia se encuentra entre los más avanzados, otros, como, por ejemplo, Bélgica y Luxemburgo, están entre los que menos (gráfico 4).

Este indicador, además, mantiene una mayor correlación con las tasas nacionales de emancipación que las variables anteriores de política de vivienda, llegando a explicar hasta un $74 \%$ de las diferencias entre países $(N=60$, coeficiente de determinación $R^{2}=0,7407$, coeficiente de correlación de Pearson de 0,86) (gráfico 5). Y, al igual que sucedía con las ayudas para el pago de la vivienda, la relación entre ambas variables también muestra un valor límite 
Gráfico 5. Correlación entre las tasas de emancipación de la población de 18 a 34 años y el indicador compuesto de alcance de la política de vivienda entre las personas emancipadas de 18 a 34 años (Europa, bienios 2006-2007, 2008-2009 y 2010-2011)

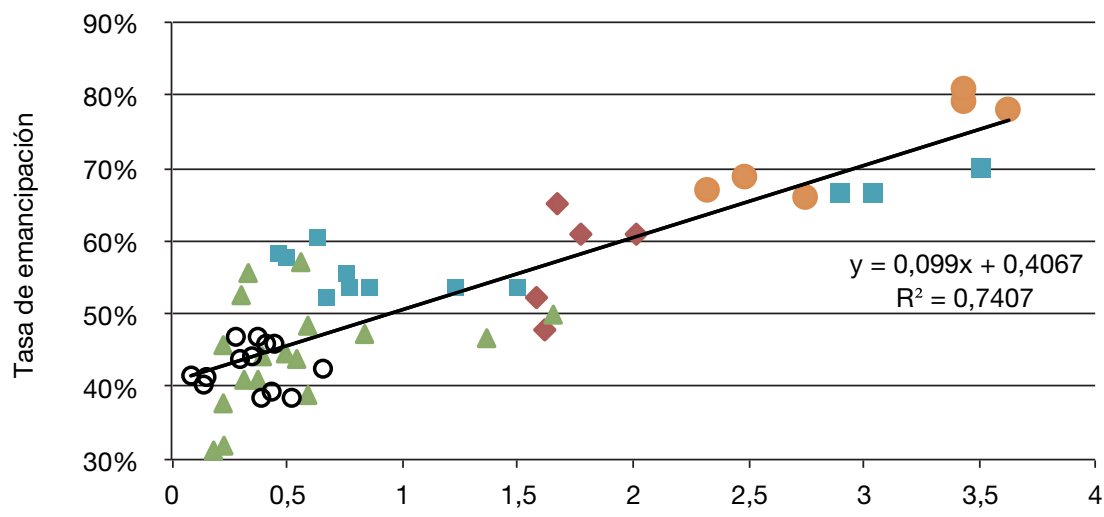

Indicador del alcance de la política de vivienda entre las personas jóvenes emancipadas

Modelo liberal

Modelo corporativista
Modelo de transición

- Modelo socialdemocrático

Fuente: elaboración propia a partir de EUROSTAT, European Survey on Income and Living Conditions (EU SILC).

por debajo del cual la correlación disminuye ostensiblemente. En particular, cuando el indicador alcanza valores superiores a 1,00, explicaría hasta un $80 \%$ de las diferentes tasas de emancipación de dichos países (Finlandia, Francia, Islandia, Irlanda y dos bienios de Austria y Chequia) $(N=19$, coeficiente de determinación $R^{2}=0,8038$, coeficiente de correlación de Pearson de 0,90$)$, y, en cambio, cuando es inferior a 1,00 $(N=41)$, el coeficiente de determinación disminuye hasta un 0,2748 (coeficiente de correlación de Pearson de 0,52).

\subsection{La accesibilidad económica de la juventud europea a la vivienda}

De forma coherente con el marco teórico, los resultados confirman que las personas jóvenes se encuentran en una peor situación en el mercado residencial en términos de accesibilidad económica que el conjunto de la población. A lo largo del periodo analizado, y con la única excepción de Chipre, en todos los países analizados las personas jóvenes emancipadas muestran mayores tasas de esfuerzo y sobreesfuerzo económico que el conjunto de la población (anexo 1, tabla 3). Es muy probable que el esfuerzo económico de la juventud chipriota emancipada sea ligeramente inferior al del total de la población debido a la inusual combinación de un considerable sistema de ayudas para el pago de los costes de la vivienda (en lo que al importe medio se refiere), con una relativa baja tasa de emancipación. 
No obstante, dichas cifras difieren de un modo significativo entre países a causa de sus profundas diferencias estructurales en aspectos como el precio de la vivienda, la tasa de empleo entre la juventud, el alcance de la política de vivienda o la tasa de emancipación. De entre todos ellos, los jóvenes griegos, británicos, españoles y húngaros son los que sufren una mayor crisis de accesibilidad económica a la vivienda, como queda de manifiesto en sus mayores tasas de esfuerzo y sobreesfuerzo económico.

Otra cuestión a destacar es la ausencia de relación entre estos dos indicadores de accesibilidad económica de la juventud emancipada y las tasas de emancipación. Ambas variables muestran una correlación extremadamente débil $(N=60)$ : un coeficiente de correlación de Pearson de 0,064 $\left(R^{2}=0,0041\right)$ para la relación entre la tasa de emancipación y el esfuerzo económico de la juventud emancipada, y de 0,1153 $\left(R^{2}=0,0133\right)$ para la relación entre la tasa de emancipación y la tasa de sobreesfuerzo económico de las personas jóvenes.

Del mismo modo, estos indicadores de accesibilidad de las personas jóvenes emancipadas mantienen una correlación insignificante con el grado de desarrollo de la política de vivienda dirigida a este grupo de edad. El coeficiente de correlación de Pearson entre el esfuerzo económico de la juventud y el índice compuesto de política de vivienda es solamente de $0,22\left(R^{2}=-0,047\right)$, y entre la tasa de sobreesfuerzo económico de las personas jóvenes y el índice compuesto, de $0,13\left(R^{2}=0,0182\right)$.

\section{Conclusiones y discusión}

A pesar de la creciente atención que recibe el enfoque individualista en el mundo académico por lo que se refiere el análisis de la transición residencial de la juventud, lo cierto es que, a nivel macro, la persistencia de grandes diferencias entre las tasas de emancipación de los países europeos pone de relieve la importancia de los factores estructurales como determinantes de dichos procesos. Sin embargo, aún existe un desconocimiento notable sobre estos factores, en particular, sobre el modo en que interactúan e influyen en las transiciones residenciales de las personas jóvenes, dado que estos no son aislables en sí mismos, sino que se enmarcan en un contexto social, económico, político y cultural determinado que debe ser considerado.

Con el propósito de reducir dicho desconocimiento, el presente estudio aporta información inédita y estructurada por modelos de estado de bienestar sobre la situación económica de la juventud en los mercados europeos de vivienda, así como sobre el grado de desarrollo de la política de vivienda dirigida a este grupo de edad y su correlación con las diferentes tasas nacionales de emancipación residencial a lo largo del sexenio 2006-2011.

La investigación confirma que el grado de desarrollo de la política de vivienda dirigida a las personas jóvenes emancipadas es un elemento estructural con una gran capacidad para explicar las diferencias en las tasas nacionales de emancipación en Europa. El alcance de los dos instrumentos de política de vivienda considerados en el estudio, la vivienda social para las personas 
jóvenes y las ayudas directas al pago de la vivienda también para la juventud guardan una relación estadística casi idéntica con las tasas de emancipación. Por separado, ambas variables explican alrededor del 65\% de la variación en las tasas de emancipación de los países europeos entre los años 2006 y 2011, y consideradas juntas a través de un indicador compuesto de política de vivienda para jóvenes, su capacidad explicativa aumenta hasta el 74\%.

Estos resultados son coherentes con el marco teórico existente, pero las explicaciones que ofrece la literatura son múltiples. La más extendida es la que defiende directamente que si el estado ofrece la ayuda necesaria (en forma de vivienda social o de ayudas económicas directas) para que las personas jóvenes puedan llevar a cabo sus transiciones residenciales, obviamente, las tasas de emancipación son mayores. No obstante, otros autores relacionan indirectamente la política de vivienda y la emancipación a través del parque de alquiler. Aquellos países con elevados niveles de intervención pública en sus sistemas de vivienda suelen tener mayores parques de vivienda en alquiler (bien por el mero hecho de disponer de un gran parque social, bien por la influencia de este en el segmento de alquiler privado, bien por la solvencia garantizada del inquilino mediante las ayudas para el pago), lo cual, a su vez, también se asocia con mayores tasas de emancipación. Por contra, los sistemas residenciales basados en la vivienda en propiedad (como sucede en los países mediterráneos y en los del modelo de transición) fomentan una tardía emancipación residencial a causa del ahorro previo necesario para poder acceder a la compra, así como de la necesidad de cierta seguridad y estabilidad laboral para asumir compromisos hipotecarios.

En cuanto a las condiciones de accesibilidad económica a la vivienda por parte de las personas jóvenes y su relación con los procesos de emancipación, es importante diferenciar entre los datos internos de cada país (fundamentalmente, comparaciones intrasistemas entre grupos de edad) y los resultantes de análisis entre países (intersistemas de vivienda). Respecto los primeros, el estudio constata que en todos los países analizados excepto en Chipre, la juventud ocupa una peor posición en el mercado en términos de accesibilidad económica que el conjunto de la población, lo cual es congruente con el marco teórico existente.

Respecto al segundo tipo de datos, el análisis revela que la accesibilidad económica de las personas jóvenes en el mercado residencial apenas explica por sí misma las diferencias entre tasas nacionales de emancipación. Tal resultado, el cual no tiene antecedentes (ni coincidentes ni opuestos) en la literatura existente, está abierto a múltiples interpretaciones cuya verificación requeriría el uso de modelos estadísticos más complejos. Es probable que la situación de la juventud en los mercados de vivienda no sea un factor estructural determinante en los procesos de emancipación y, en cambio, sí lo sea el nivel de apoyo público a través de la política de vivienda que las personas reciben para superar dichas dificultades. También cabe la posibilidad de que los indicadores empleados presenten problemas de comparabilidad, es decir, que no reflejen la verdadera magnitud de las dificultades de accesibilidad de las personas jóvenes en 
determinados sistemas residenciales, dado que están basados únicamente en dos variables (ingresos disponibles y costes residenciales) y aplicados de forma lineal a países con realidades socioeconómicas muy dispares. Otra explicación radica en la burbuja residencial. A finales de los noventa, el precio de la vivienda empezó a subir con fuerza en la mayoría de mercados europeos, expulsando de los mismos a un segmento de población cada vez mayor. Tras el estallido de la burbuja en 2007-2008, por lo general, las condiciones de accesibilidad económica siguieron deteriorándose, esta vez, a causa de la crisis. Por consiguiente, este estudio abarca los años anteriores y posteriores al estallido de la burbuja, un espacio de tiempo muy particular de la historia reciente de los sistemas de vivienda europeos cuyos indicadores de accesibilidad previsiblemente siguen una dinámica propia independiente del resto de variables residenciales.

Del mismo modo, los indicadores de accesibilidad económica de la juventud en los mercados residenciales tampoco mantienen correlación alguna con el grado de desarrollo de la política de vivienda dirigida a la juventud. Tal circunstancia podría responder a la limitada capacidad de intervención de que gozan los poderes públicos en la actualidad en este campo. Desde los años ochenta, y aunque con intensidades diferentes, en toda Europa se ha producido una reducción del gasto público en política de vivienda y una paulatina privatización del parque social, lo que indudablemente ha ido menoscabando el alcance de las políticas de vivienda en el continente.

Por su parte, a pesar de que, como señalábamos anteriormente, no pueden inferirse del estudio relaciones de causalidad entre variables por las características del mismo, merece especial atención, principalmente por su interés en el diseño de políticas de vivienda, la posible existencia de un determinado umbral en materia de ayudas para el pago de la vivienda por debajo del cual las ayudas no mantienen correlación con las tasas de emancipación.

Asimismo, la investigación confirma la validez del análisis de los procesos de emancipación y de los sistemas de vivienda desde los diferentes modelos de estado de bienestar. Tanto las políticas de vivienda como los procesos de emancipación se desarrollan de un modo específico en cada país en función de sus singularidades sociodemográficas, económicas, culturales, políticas e institucionales. En concreto, aquellos países en los que el estado, el mercado de trabajo y la familia interactúan de un modo similar para atender a las necesidades de los ciudadanos desarrollan un modelo propio de emancipación a partir de su noción de juventud y de los derechos que reconocen a esta en materia de vivienda. Por este motivo:

1. Los países del modelo socialdemocrático muestran mayores tasas de emancipación y una política de vivienda mucho más desarrollada que el resto.

2. Los países liberales, aunque en menor grado, también disfrutan de una política de vivienda amplia y de elevadas tasas de emancipación.

3. Por el contrario, en los países del modelo de transición y del Mediterráneo, la política de vivienda para la juventud es claramente insuficiente y las tasas de emancipación, muy bajas. 
En este esquema, el único modelo que presenta dificultades es el corporativista. Tanto la disparidad en las tasas de emancipación de los países del mismo como en el grado de desarrollo de su política de vivienda, impiden identificar un modelo de emancipación propiamente corporativista.

Por último, señalar que hay un amplio campo para futuras investigaciones sobre el tema objeto de estudio. En concreto, la aplicación de un modelo multivariado multinivel sobre una serie histórica más larga que la EU SILC que permitiera incorporar en el estudio todos los países de la Unión Europea, así como otras variables estructurales, proporcionaría resultados más concluyentes y posibilitaría el establecimiento de relaciones causales. Por ejemplo, para la definición de los aspectos técnicos y presupuestarios de las políticas de vivienda dirigidas a la juventud, sería particularmente relevante ahondar en la posible existencia de umbrales en materia de ayudas para el pago de la vivienda por debajo de los cuales dicho instrumento no incide en los procesos de emancipación. Igualmente, también sería de gran interés investigar el modo en que las condiciones de accesibilidad económica de las personas jóvenes, desde un enfoque estructural comparado, influyen en las transiciones residenciales juveniles.

\section{Referencias bibliográficas}

Aassve, Arnstein; Billari, Francesco C.; Mazzuco, Stefano y Ongaro, Fausta (2002). «Leaving Home: A Comparative Analysis of ECHP data». Journal of European Social Policy, 12, 259-275.

Allen, Judith (2006). «Welfare Regimes, Welfare Systems and Housing in Southern Europe». International Journal of Housing Policy [en línea], 6 (3), 251-277. <http://dx.doi.org/10.1080/14616710600973102>.

Allen, Judith; Barlow, James; Leal, Jesús; Maloutas, Thomas y Padovani, Liliana (2004). Housing and Welfare in Southern Europe. Oxford: Blackwell Publishing [en línea]. <http://dx.doi.org/10.1002/9780470757536>.

Andersson, Roger (2002). «Some reflections on housing and family well-being». Housing Studies [en línea], 17 (1), 27-31. <http://dx.doi.org/10.1080/02673030120105866>.

Andrews, Dan; Caldera, Aida y Johansson, Åsa (2011). Housing Markets and Structural Policies in OECD Countries. París: OECD Economics Department Working Papers, 836. OECD Publishing.

Anxo, Dominique; Bosch, Gerhard y Rubery, Jill (eds.) (2010). The Welfare State and Life Transitions: A European Perspective. Cheltenham: Edward Elgar.

Ayllón, Sara (2009). «Poverty and living arrangements among youth in Spain, 19802005». Demographic Research [en línea], 20 (17), 403-434. $<$ http://dx.doi.org/10.4054/DemRes.2009.20.17>.

Balchin, Paul (ed.) (1996). Housing Policy in Europe [en línea]. Londres: Routledge. <http://dx.doi.org/10.4324/9780203436417>.

Barlow, James y Duncan, Simon (1994). Success and Failure in Housing Provision: European Systems Compared. Londres: Pergamon.

BeCK, Ulrich y BeCK-GernsheIm, Elisabeth (2002). Individualization: Institutionalized Individualism and its Social and Political Consequences. Londres: Sage. 
Berthoud, Richard y Iacovou, Maria (eds.) (2004). Social Europe: Living Standards and Welfare States. Cheltenham y Northampton: Edward Elgar.

Biggart, Andy y Walther, Andreas (2006). «Coping with Yo-Yo-Transitions: Young Adults Struggle for Support, between family and State in Comparative Perspective». En: Leccardi, Carmen y Ruspini, Elisabetta (eds.). A New Youth? Young People, Generations and Family Life. Aldershot: Ashgate.

Brannen, Julia; Lewis, Suzan; Nilsen, Ann y Smithson, Janet (eds.) (2002). Young Europeans, work and family: Futures in transition [en línea]. Londres: Routledge. <http://dx.doi.org/10.4324/9780203471852>.

Breen, Richard y BuChMAnN, Marlis (2002). «Institutional variation and the position of young people: A comparative perspective». The Annals of the American Academy of Political and Social Sciences [en línea], 580, 288-305. <http://dx.doi.org/10.1177/0002716202580001012>.

BrüCKNER, Hannah y MAYER, Karl Ulrich (2005). «De-standardization of the life course: What it Might Mean? And if it Means Anything, Whether it Actually Took Place?». Advances in Life Course Research [en línea], 9, 27-53. <http://dx.doi.org/10.1016/S1040-2608(04)09002-1>.

Buchmann, Marlis (1989). The script of life in modern society: Entry into adulthood in a changing world. Chicago: University of Chicago Press.

Buchmann Marlis y Kriesi, Irene (2011). "Transition to adulthood in Europe». Annual Review of Sociology [en línea], 37, 481- 503. <http://dx.doi.org/10.1146/annurev-soc-081309-150212>.

Cantó, Olga y Mercader, Magda (2001a). «Young people leaving home: The impact on poverty in Spain». En: Bradbury, Bruce; Jenkins, Stephen P. y MickleWRIGHT, John (eds.). The Dynamics of Child Poverty in Industrialised Economics [en línea]. Cambridge: Cambridge University Press. <http://dx.doi.org/10.1017/CBO9780511522147>.

- (2001b). «Pobreza y familia: ¿Son los jóvenes una carga o una ayuda?». Papeles de Economía Española, 88, 151-165.

Castles, Francis G. (1998). "The Really Big Trade-Off: Home Ownership and the Welfare State in the New World and the Old». Acta Politica [en línea], 33 (1), 5-19. <http://dx.doi.org/10.1080/14036090510032727>.

Castles, Francis G. y Ferrera, Maurizio (1996). «Home Ownership and the Welfare State: Is southern Europe Different?». South European Society and Politics [en línea], 1 (2), 163-184. <http://dx.doi.org/10.1080/13608749608539470>.

CECODHAS (2012). Impact of the Crisis and Austerity Measures on the Social Housing Sector. Bruselas: CECODHAS Housing Europe's Observatory, Research Briefing, CECODHAS Housing Europe.

Chandler, Joan; Williams, Malcom; Maconachie, Moira; Collett, Tracey y DodGEON, Brian (2004). "Living alone: its place in household formation and change». Sociological Research Online [en línea], 3 (9).

<http://dx.doi.org/10.5153/sro.971>.

Chanvril, Flora; Cousteaux, Anne-Sophie; Le Hay, Viviane; Lesnard, Laurent; Mechinaud, Chloé y Sauger, Nicolas (2009). La parentalité en Europe: Analyse séquentielle des trajectoires d'entrée dans l'âge adulte à partir de l'Enquête sociale européenne. París: Caisse nationale des Allocations familiales, Dossiers d'études n ${ }^{\circ} 122$.

Coles, Bob (1995). Youth and social policy: Youth citizenship and young careers. Londres: UCL Press. 
Cote, James (2002). «The Role of Identity Capital in the Transition to Adulthood: The Individualization Thesis Examined" [en línea]. Journal of Youth Studies 5 (2), 117-134. <http://dx.doi.org/10.1080/13676260220134403>.

Cote, James y Bynner, John M. (2008). "Changes in the transition to adulthood in the UK and Canada: The role of structure and agency in emerging adulthood». Journal of Youth Studies [en línea], 11 (3), 251-268. <http://dx.doi.org/10.1080/13676260801946464>.

Czischke, Darinka y Pittini, Alice (2007). Housing Europe 2007: Review of social, co-operative and public housing in the 27 EU member states. Bruselas: CECODHAS, European Social Housing Observatory.

Domanski, Henryk (2008). "Housing conditions». En: Alber, Jens; Fahey, Tony y Saraceno, Chiara (eds.). Handbook of Quality of Life in the Enlarged European Union. Londres: Routledge.

EGRIS (2001). «Misleading Trajectories: Transition Dilemmas of Young Adults in Europe». Journal of Youth Studies [en línea], 4 (1), 101-118. <http://dx.doi.org/10.1080/13676260120028574>.

Elzinga, Cees H. y Liefbroer, Aart C. (2007). «De-standardization of family-life trajectories of young adults: A crossnational comparison using sequence analysis». European Journal of Population [en línea], 23 (3-4), 225-250. <http://dx.doi.org/10.1007/s10680-007-9133-7>.

Emmanuel, Dimitris (2013). «Balancing autonomy, status and family in the transition to adulthood: Class and housing aspects of the Southern European model in Athens, 1987-2004». En: Forrest, Ray y NGai-Ming, Yip (eds.). Housing Young People: Transitions, Trajectories and Generational Fractures. Oxon: Routledge.

Enström, Cecilia (2009). The Effect of Parental Wealth on Tenure Choice: A Study of Family Background and Young Adults Housing Situation. Estocolmo: Institute for Futures Studies.

Esping-Andersen, Gøsta (1990). The Three Worlds of Welfare Capitalism. Cambridge: Polity Press.

Evans, Karen y Furlong, Andy (1997). "Metaphors of youth transitions: Niches, pathways, trajectories or navigations». En: Bynner, John; Chisholm, Lynne y Furlong, Andy (eds.). Youth, Citizenship and Social Change in a European Context. Aldershot: Ashgate.

Fahey, Tony y Norris, Michelle (2009). Housing and the Welfare State: An Overview. Dublín: University College Dublin. UCD School of Applied Social Science Working Paper Series 09.

- (2011). «Housing in the Welfare State: Rethinking the Conceptual Foundations of Comparative Housing Policy Analysis». International Journal of Housing Policy [en línea], 11 (4), 439-452.

<http://dx.doi.org/10.1080/14616718.2011.626606>.

Feijten, Peteke y Mulder, Clara (2005). «Life-course experience and housing quality». Housing Studies [en línea], 20, 571-587. <http://dx.doi.org/10.1080/02673030500114474>.

Fenger, Menno (2007). "Welfare Regimes in Central and Eastern Europe: Incorporating Post-Communist Countries in a Welfare Regime Typology». Contemporary Issues and Ideas in Social Sciences, 3 (2), 1-30.

Ferreira, Leonor Vasconcelos y Figueiredo, Adelaide (2005). Welfare Regimes in the EU 15 and in the Enlarged Europe: An exploratory analysis. Oporto: Universidade do Porto. FEW Working Paper no. 176. Faculdade de Economia. 
Ferrera, Maurizio (1996). «The "Southern Model” of Welfare in Social Europe». Journal of European Social Policy [en línea], 6, 17-37. <http://dx.doi.org/10.1177/095892879600600102>.

Fitzpatrick, Suzanne y Stephens, Mark (2007a). «Welfare Regimes, Housing Systems and Homelessness: How are they linked?». European Journal of Homelessness, $1,201-211$.

- (2007b). An International Review of Homelessness and Social Housing Policy. Londres: Communities and Local Government.

Fuchs, Susanne (2008). Welfare State Formation in the Enlarged European Union Patterns of Reform in the Post-Communist New Member States. Berlín: HSoG Publishing. Hertie School of Governance. Working papers, 14.

Furlong, Andy y Cartmel, Fred (2007). Young people and social change: New perspectives. Berkshire: Open University Press.

Galland, Olivier (1991). Sociologie de la jeunesse. París: Armand Colin Press.

Harloe, Michael (1995). The people's home: Social rented housing in Europe and America. Oxford: Blackwell.

Hegedüs, József (2008). «Social Housing in Transition Countries». En: Scanlon, Kathleen y Whitenead, Christine (eds.). Social Housing in Europe II: A review of policies and outcomes. Londres: London School of Economics and Political Science.

Hegedüs, József; Lux, Martin y Teller, Nora (eds.) (2013). Social housing in transition countries. Londres: Routledge.

Hegedüs, József y Teller, Nora (2004). «The social and economic significance of housing management». En: Iliev, Dimo y Carraz, Catherine (eds.). Housing in Eastern Europe (solving a puzzle of challenges). París: World Bank y Council of Europe Development Bank.

- (2005). «Development of the Housing Allowance Programmes in Hungary in the Context of CEE Transitional Countries». European Journal of Housing Policy [en línea], 5 (2), 187-209. <http://dx.doi.org/10.1080/14616710500162699>.

Hegedüs, József y Tosics, Iván (1996). «Disintegration of East-European Housing Modell». En: Clapham, David; Hegedüs, József; Kintrea, Keith y Tosics, Iván (eds.). Housing Privatisation in Eastern Europe. Westport: Greenwood Press.

Hoekstra, J. (2003). «Housing and the Welfare State in the Netherlands: An Application of Esping-Andersen's Typology». Housing, Theory and Society [en línea], 20 (20), 58-71. <http://dx.doi.org/10.1080/14036090310000634>.

IAcovou, Maria (2002). «Regional Differences in the Transition to Adulthood». The Annals of the American Academy of Political and Social Sciences [en línea], 580, 40-69. <http://dx.doi.org/10.1177/0002716202580001003>.

- (2004). «Patterns of family living». En: Berthoud, Richard y Iacovou, Maria (eds.). Social Europe: Living Standards and Welfare States. Cheltenham y Northampton: Edward Elgar.

Jones, Gill y Wallace, Claire (1992). Youth, Family and Citizenship. Buckingham: Open University Press.

Kemeny, Jim (1995). From Public Housing to Social Renting: Rental Policy Strategies in Comparative Perspective. Londres: Routledge.

- (2001). "Comparative Housing and Welfare: Theorising the Relationship». Journal of Housing and the Built Environment [en línea], 16, 53-70. <http://dx.doi.org/10.1023/A:1011526416064>. 
- (2005). "The Really Big Trade-Off between Home Ownership and Welfare: Castles' Evaluation of the 1980 Thesis, and a Reformulation 25 Years on». Housing, Theory and Society [en línea], 22, 59-75. <http://dx.doi. org/10.1080/14036090510032727>.

Kendig, Hal (1990). «A Life Course Perspective on Housing Attainment». En: Myers, Dowell (ed.). Housing Demography. Madison: University of Wisconsin.

Keune, Maarten (2006). "The European Social Model and Enlargement». En: Jepsen, Maria y Serrano, Amparo (eds.). Unwrapping the European social model. Bristol: Policy Press.

KoHLI, Martin (2007). «The Institutionalization of the Life Course: Looking Back to Look Ahead». Research in Human Development [en línea], 4 (3-4), 253-271. <http://dx.doi.org/10.1080/15427600701663122>.

Kornai, János (1992). The Socialist System: The Political Economy of Communism. Oxford: Oxford University Press. <http://dx.doi.org/10.1093/0198287763.001.0001>.

Laino, Elsa y Pittini, Alice (2011). Housing Europe Review 2012: The nuts and bolts of European social housing systems. Bruselas: CECODHAS Housing Europe.

LeIbFried, Stephan (1992). "Towards a European Welfare State?: On integrating poverty regimes into the European Community». En: Ferge, Zsuzsa y Kolberg, Jon-Eivind (eds.). Social Policy in a Changing Europe. Frankfurt: Westview Press.

Lieberg, Mats (2013). "Youth housing and exclusion in Sweden». En: Forrest, Ray y Ngat-Ming, Yip (eds.). Housing Young People: Transitions, Trajectories and Generational Fractures. Oxon: Routledge.

Mandic, Srna (2008). "Home-leaving and its structural determinants in Western and Eastern Europe: An exploratory study». Housing Studies [en línea], 23 (4), 615-637. <http://dx.doi.org/10.1080/02673030802112754>.

Mandic, Srna y Cirman, Andreja (2012). «Housing conditions and their structural determinants: Comparisons within the enlarged EU». Urban Studies [en línea], 49 (4), 777-793. <http://dx.doi.org/10.1177/0042098011405688>.

Matznetter, Walter (2002). «Social Housing in a Conservative welfare State: Austria as an Example». Urban Studies [en línea], 39 (2), 265-282. <http://dx.doi.org/10.1080/00420980120102966>.

Mckee, Kim (2012). "Young people, homeownership and future welfare». Housing Studies [en línea], 27 (6), 853-862. <http://dx.doi.org/10.1080/02673037.2012.714463>.

Mulder, Clara (2006). "Home-ownership and family formation». Journal of Housing and the Built Environment [en línea], 21, 281-298. <http://dx.doi.org/10.1007/s10901-006-9050-9>.

Mulder, Clara; Clark, William A.V. y Wagner, Michael (2002). «A comparative analysis of leaving home in the United States, the Netherlands and West Germany». Demographic Research [en línea], 7, 565-592. <http://dx.doi.org/10.4054/DemRes.2002.7.17>.

Nico, Magda (2013). Housing and Residential Autonomy. EU-CoE youth partnership policy sheet. Bruselas: European Union y Council of Europe.

PaIs, José (2003). «The multiple faces of the future in the labyrinth of life». Journal of Youth Studies [en línea], 6 (2), 115-126. <http://dx.doi.org/10.1080/1367626032000110264>. 
PARISI, Lavinia (2008). «Leaving home and the chances of being poor: The case of young people in Southern European countries». Labour [en línea], 22, 89-114. <http://dx.doi.org/10.1111/j.1467-9914.2008.00414.x>.

Pittini, Alice (2012). Housing Affordability in The EU: Current Situation and Recent Trends. Bruselas: CECODHAS Housing Europe's Observatory, Research Briefing. CECODHAS Housing Europe.

Pittini, Alice y Baloup, Juliette (2012). Profile of social housing residents. Bruselas: CECODHAS, European Social Housing Observatory.

Roberts, Ken (2009). Youth in Transitions: Eastern Europe and the West. Houndmills: Palgrave Macmillan.

- (2010). «Is post-communism still a useful concept?: Evidence from studies of young people's life stage transitions». Annales [en línea], 20 (1), 1-12.

Rys, Vladimir (2001). «Transition Countries of Central Europe entering the European Union: Some Social Protection Issues». International Social Security Review [en línea], 52 (2-3), 177-189. <http://dx.doi.org/10.1111/1468-246X.00098>.

Schizzerotto, Antonio y Lucchini, Mario (2004). «Transitions to adulthood». En: Berthoud, Richard y Iacovou, Maria (eds.). Social Europe: Living Standards and Welfare States. Cheltenham y Northampton: Edward Elgar.

Shanahan, Michael J. (2000). «Pathways to Adulthood in Changing Societies: Variability and Mechanisms in Life Course Perspective». Annual Review of Sociology [en línea], 26 (1), 667-692. <http://dx.doi.org/10.1146/annurev.soc.26.1.667>.

Sмiтh, Douglas I. (2009). "Changes in transitions: The role of mobility, class and gender». Journal of Education and Work [en línea], 22 (5), 369-390. <http://dx.doi.org/10.1080/13639080903454001>.

Stephens, Mark; Fitzpatrick, Suzanne; Elsinga, Marja; Van Steen, Guido y Chzhen, Yekaterina (2010). Study on housing and exclusion: Welfare policies, housing provision and labour markets. Bruselas: European Commission.

TaYlor-Gooby, Peter (2004). New risks, new welfare: The transformation of the European welfare state. Oxford: Oxford University Press.

Valentine, Gill (2003). «Boundary crossings: Transitions from childhood to adulthood». Children's Geographies [en línea], 1, 37-52. <http://dx.doi.org/10.1080/14733280302186>.

VAn de Velde, Cécile (2008). Devenir adulte: Sociologie comparée de la jeunesse en Europe. París: Presses Universitaires de France. Le Lien Social.

Vogel, Joachim (2002). «European Welfare regimes and the transition to adulthood: A comparative and longitudinal perspective». Social Indicators Research [en línea], 59 (3), 275-299. <http://dx.doi.org/10.1023/A:1019627604669>.

Walther, Andreas (2006). "Regimes of youth transitions: Choice, flexibility and security in young people's experiences across different European contexts». Young [en línea], 14 (1), 119-141. <http://dx.doi.org/10.1177/1103308806062737>.

Whitehead, Christine y Scanlon, Kathleen (eds.) (2007). Social Housing in Europe. Londres: London School of Economics and Political Science.

WidMER, Eric D. y Ritschard, Gilbert (2009). "The de-standardization of the life course: Are men and women equal?». Advances in Life Course Research [en línea], 14 (1-2), 28-39. <http://dx.doi.org/10.1016/j.alcr.2009.04.001>. 


\section{Anexo I}

Tabla 3. Aspectos de accesibilidad económica a la vivienda según grupo de edad (Europa, 2006-2011)

\begin{tabular}{|c|c|c|c|c|c|c|c|c|c|c|c|}
\hline & & & \multicolumn{3}{|c|}{$\begin{array}{l}\text { Coste de la vivienda } \\
\text { respecto el total de } \\
\text { ingresos disponibles } \\
\text { del hogar (esfuerzo } \\
\text { económico medio de } \\
\text { la población) }\end{array}$} & \multicolumn{3}{|c|}{$\begin{array}{l}\text { Porcentaje de } \\
\text { población en situación } \\
\text { de sobreesfuerzo } \\
\text { económico a la vivienda } \\
\text { (esfuerzo económico } \\
>40 \% \text { ) }\end{array}$} & \multicolumn{3}{|c|}{$\begin{array}{l}\text { Porcentaje de población } \\
\text { que vive en una vivienda } \\
\text { social }\end{array}$} \\
\hline & & & $\begin{array}{l}2006- \\
2007\end{array}$ & $\begin{array}{l}2008- \\
2009\end{array}$ & $\begin{array}{l}2010- \\
2011\end{array}$ & $\begin{array}{l}2006- \\
2007\end{array}$ & $\begin{array}{c}2008- \\
2009\end{array}$ & $\begin{array}{l}2010- \\
2011\end{array}$ & $\begin{array}{l}2006- \\
2007\end{array}$ & $\begin{array}{l}2008- \\
2009\end{array}$ & $\begin{array}{l}2010- \\
2011\end{array}$ \\
\hline \multirow{4}{*}{$\begin{array}{l}\text { Modelo } \\
\text { socialdemocrático }\end{array}$} & Islandia & Total población & $19,2 \%$ & $21,7 \%$ & $22,5 \%$ & $11,5 \%$ & $10,4 \%$ & $10,1 \%$ & $6,4 \%$ & $6,3 \%$ & $7,0 \%$ \\
\hline & & $\begin{array}{l}\text { Jóvenes } \\
\text { emancipados }\end{array}$ & $23,0 \%$ & $26,0 \%$ & $26,6 \%$ & $12,6 \%$ & $15,5 \%$ & $16,2 \%$ & $12,8 \%$ & $15,4 \%$ & $16,3 \%$ \\
\hline & Finlandia & Total población & $13,8 \%$ & $16,9 \%$ & $16,0 \%$ & $4,3 \%$ & $4,7 \%$ & $4,3 \%$ & $16,1 \%$ & $15,3 \%$ & $14,4 \%$ \\
\hline & & $\begin{array}{l}\text { Jóvenes } \\
\text { emancipados }\end{array}$ & $21,9 \%$ & $22,7 \%$ & $21,9 \%$ & $8,6 \%$ & $8,5 \%$ & $8,3 \%$ & $29,2 \%$ & $28,9 \%$ & $26,9 \%$ \\
\hline \multirow{8}{*}{$\begin{array}{l}\text { Modelo } \\
\text { corporativista }\end{array}$} & Francia & Total población & $14,4 \%$ & $15,4 \%$ & $16,8 \%$ & $5,6 \%$ & $4,1 \%$ & $7,2 \%$ & $15,2 \%$ & $19,1 \%$ & $17,5 \%$ \\
\hline & & $\begin{array}{l}\text { Jóvenes } \\
\text { emancipados }\end{array}$ & $22,9 \%$ & $23,1 \%$ & $25,1 \%$ & $11,8 \%$ & $10,0 \%$ & $13,2 \%$ & $26,1 \%$ & $22,1 \%$ & $22,2 \%$ \\
\hline & Bélgica & Total población & $18,7 \%$ & $21,6 \%$ & $21,2 \%$ & $10,0 \%$ & $10,6 \%$ & $9,9 \%$ & $6,7 \%$ & $7,2 \%$ & $7,1 \%$ \\
\hline & & $\begin{array}{l}\text { Jóvenes } \\
\text { emancipados }\end{array}$ & $27,1 \%$ & $26,7 \%$ & $27,5 \%$ & $15,9 \%$ & $15,2 \%$ & $16,0 \%$ & $6,2 \%$ & $7,2 \%$ & $8,7 \%$ \\
\hline & Austria & Total población & $15,6 \%$ & $17,2 \%$ & $17,8 \%$ & $5,2 \%$ & $4,9 \%$ & $5,6 \%$ & $5,9 \%$ & $9,2 \%$ & $10,5 \%$ \\
\hline & & $\begin{array}{l}\text { Jóvenes } \\
\text { emancipados }\end{array}$ & $24,0 \%$ & $23,7 \%$ & $24,5 \%$ & $11,3 \%$ & $11,1 \%$ & $12,0 \%$ & $10,0 \%$ & $14,9 \%$ & $18,3 \%$ \\
\hline & Luxemburgo & Total población & $11,3 \%$ & $13,4 \%$ & $13,6 \%$ & $4,4 \%$ & $3,7 \%$ & $4,2 \%$ & $3,5 \%$ & $4,1 \%$ & $2,5 \%$ \\
\hline & & $\begin{array}{l}\text { Jóvenes } \\
\text { emancipados }\end{array}$ & $22,3 \%$ & $22,2 \%$ & $20,8 \%$ & $9,2 \%$ & $8,7 \%$ & $8,8 \%$ & $7,3 \%$ & $6,2 \%$ & $3,4 \%$ \\
\hline \multirow[t]{4}{*}{ Modelo liberal } & Reino Unido & Total población & $24,7 \%$ & $27,2 \%$ & $27,5 \%$ & $16,7 \%$ & $16,7 \%$ & $17,2 \%$ & $14,7 \%$ & $16,9 \%$ & $16,4 \%$ \\
\hline & & $\begin{array}{l}\text { Jóvenes } \\
\text { emancipados }\end{array}$ & $34,6 \%$ & $35,1 \%$ & $35,3 \%$ & $25,0 \%$ & $26,6 \%$ & $26,6 \%$ & $14,8 \%$ & $16,5 \%$ & $17,7 \%$ \\
\hline & Irlanda & Total población & $10,5 \%$ & $13,6 \%$ & $14,8 \%$ & $3,0 \%$ & $3,7 \%$ & $5,1 \%$ & $12,3 \%$ & $13,5 \%$ & $12,5 \%$ \\
\hline & & $\begin{array}{l}\text { Jóvenes } \\
\text { emancipados }\end{array}$ & $21,8 \%$ & $23,6 \%$ & $25,6 \%$ & $10,3 \%$ & $10,7 \%$ & $14,1 \%$ & $13,5 \%$ & $13,0 \%$ & $15,8 \%$ \\
\hline \multirow{6}{*}{$\begin{array}{l}\text { Modelo } \\
\text { mediterráneo }\end{array}$} & Chipre & Total población & $17,9 \%$ & $21,4 \%$ & $19,7 \%$ & $2,5 \%$ & $2,2 \%$ & $2,9 \%$ & $0,8 \%$ & $0,5 \%$ & $0,6 \%$ \\
\hline & & $\begin{array}{l}\text { Jóvenes } \\
\text { emancipados }\end{array}$ & $14,8 \%$ & $15,0 \%$ & $18,3 \%$ & $4,1 \%$ & $5,0 \%$ & $9,3 \%$ & $0,7 \%$ & $0,8 \%$ & $0,9 \%$ \\
\hline & España & Total población & $13,2 \%$ & $19,9 \%$ & $21,1 \%$ & $6,7 \%$ & $11,5 \%$ & $12,2 \%$ & $2,9 \%$ & $3,0 \%$ & $2,7 \%$ \\
\hline & & $\begin{array}{l}\text { Jóvenes } \\
\text { emancipados }\end{array}$ & $23,1 \%$ & $28,3 \%$ & $30,7 \%$ & $13,3 \%$ & $19,5 \%$ & $22,5 \%$ & $2,1 \%$ & $2,3 \%$ & $2,9 \%$ \\
\hline & Grecia & Total población & $25,4 \%$ & $31,0 \%$ & $30,6 \%$ & $16,5 \%$ & $22,4 \%$ & $19,9 \%$ & $1,0 \%$ & $0,5 \%$ & $0,9 \%$ \\
\hline & & $\begin{array}{l}\text { Jóvenes } \\
\text { emancipados }\end{array}$ & $34,7 \%$ & $47,1 \%$ & $42,8 \%$ & $30,3 \%$ & $50,0 \%$ & $44,0 \%$ & $1,4 \%$ & $0,7 \%$ & $1,8 \%$ \\
\hline
\end{tabular}


Tabla 3. Aspectos de accesibilidad económica a la vivienda según grupo de edad (Europa, 2006-2011) (continuación)

\begin{tabular}{|c|c|c|c|c|c|c|c|c|c|c|c|}
\hline & & & \multicolumn{3}{|c|}{$\begin{array}{l}\text { Coste de la vivienda } \\
\text { respecto el total de } \\
\text { ingresos disponibles } \\
\text { del hogar (esfuerzo } \\
\text { económico medio de } \\
\text { la población) }\end{array}$} & \multicolumn{3}{|c|}{$\begin{array}{l}\text { Porcentaje de } \\
\text { población en situación } \\
\text { de sobreesfuerzo } \\
\text { económico a la vivienda } \\
\text { (esfuerzo económico } \\
>40 \% \text { ) }\end{array}$} & \multicolumn{3}{|c|}{$\begin{array}{l}\text { Porcentaje de población } \\
\text { que vive en una vivienda } \\
\text { social }\end{array}$} \\
\hline & & & $\begin{array}{c}2006- \\
2007\end{array}$ & $\begin{array}{c}2008- \\
2009\end{array}$ & $\begin{array}{c}2010- \\
2011\end{array}$ & $\begin{array}{l}2006- \\
2007\end{array}$ & $\begin{array}{c}2008- \\
2009\end{array}$ & $\begin{array}{l}2010- \\
2011\end{array}$ & $\begin{array}{l}2006- \\
2007\end{array}$ & $\begin{array}{l}2008- \\
2009\end{array}$ & $\begin{array}{c}2010- \\
2011\end{array}$ \\
\hline \multirow{4}{*}{$\begin{array}{l}\text { Modelo } \\
\text { mediterráneo }\end{array}$} & \multirow[t]{2}{*}{ Portugal } & Total población & $13,6 \%$ & $16,4 \%$ & $14,6 \%$ & $6,0 \%$ & $7,3 \%$ & $5,3 \%$ & $7,2 \%$ & $5,9 \%$ & $4,8 \%$ \\
\hline & & $\begin{array}{l}\text { Jóvenes } \\
\text { emancipados }\end{array}$ & $20,3 \%$ & $22,5 \%$ & $20,6 \%$ & $9,7 \%$ & $13,7 \%$ & $11,5 \%$ & $5,7 \%$ & $2,8 \%$ & $4,1 \%$ \\
\hline & \multirow[t]{2}{*}{ Italia } & Total población & $17,0 \%$ & $17,7 \%$ & $17,0 \%$ & $10,0 \%$ & $7,8 \%$ & $7,8 \%$ & $5,3 \%$ & $5,3 \%$ & $5,4 \%$ \\
\hline & & $\begin{array}{l}\text { Jóvenes } \\
\text { emancipados }\end{array}$ & $27,2 \%$ & $24,4 \%$ & $25,5 \%$ & $19,1 \%$ & $15,4 \%$ & $18,0 \%$ & $5,5 \%$ & $5,1 \%$ & $4,2 \%$ \\
\hline \multirow{14}{*}{$\begin{array}{l}\text { Modelo de } \\
\text { transición }\end{array}$} & \multirow[t]{2}{*}{ Estonia } & Total población & $14,8 \%$ & $15,3 \%$ & $18,4 \%$ & $6,4 \%$ & $4,0 \%$ & $7,0 \%$ & $1,5 \%$ & $1,8 \%$ & $2,3 \%$ \\
\hline & & $\begin{array}{l}\text { Jóvenes } \\
\text { emancipados }\end{array}$ & $17,4 \%$ & $18,7 \%$ & $21,4 \%$ & $8,0 \%$ & $8,4 \%$ & $11,3 \%$ & $3,5 \%$ & $4,2 \%$ & $6,9 \%$ \\
\hline & \multirow[t]{2}{*}{ Rep. Checa } & Total población & $22,0 \%$ & $23,7 \%$ & $23,2 \%$ & $10,5 \%$ & $11,0 \%$ & $10,6 \%$ & $18,1 \%$ & $15,8 \%$ & $10,5 \%$ \\
\hline & & $\begin{array}{l}\text { Jóvenes } \\
\text { emancipados }\end{array}$ & $25,4 \%$ & $26,0 \%$ & $24,5 \%$ & $13,9 \%$ & $15,5 \%$ & $13,0 \%$ & $22,0 \%$ & $19,1 \%$ & $10,7 \%$ \\
\hline & \multirow[t]{2}{*}{ Lituania } & Total población & $15,4 \%$ & $15,9 \%$ & $21,8 \%$ & $5,9 \%$ & $5,2 \%$ & $12,0 \%$ & $1,5 \%$ & $1,5 \%$ & $1,0 \%$ \\
\hline & & $\begin{array}{l}\text { Jóvenes } \\
\text { emancipados }\end{array}$ & $17,7 \%$ & $19,4 \%$ & $26,8 \%$ & $7,5 \%$ & $9,0 \%$ & $19,2 \%$ & $5,3 \%$ & $3,0 \%$ & $1,8 \%$ \\
\hline & \multirow[t]{2}{*}{ Letonia } & Total población & $17,7 \%$ & $18,7 \%$ & $21,9 \%$ & $10,4 \%$ & $9,5 \%$ & $11,4 \%$ & $7,2 \%$ & $4,1 \%$ & $4,6 \%$ \\
\hline & & $\begin{array}{l}\text { Jóvenes } \\
\text { emancipados }\end{array}$ & $18,5 \%$ & $18,8 \%$ & $24,0 \%$ & $8,5 \%$ & $8,9 \%$ & $14,7 \%$ & $7,6 \%$ & $5,4 \%$ & $5,3 \%$ \\
\hline & \multirow[t]{2}{*}{ Polonia } & Total población & $21,3 \%$ & $21,4 \%$ & $22,9 \%$ & $11,3 \%$ & $9,0 \%$ & $10,9 \%$ & $1,1 \%$ & $1,0 \%$ & $1,2 \%$ \\
\hline & & $\begin{array}{l}\text { Jóvenes } \\
\text { emancipados }\end{array}$ & $25,4 \%$ & $22,3 \%$ & $23,3 \%$ & $14,9 \%$ & $11,3 \%$ & $12,7 \%$ & $3,1 \%$ & $3,0 \%$ & $3,4 \%$ \\
\hline & \multirow[t]{2}{*}{ Hungría } & Total población & $21,3 \%$ & $23,7 \%$ & $25,8 \%$ & $11,6 \%$ & $10,3 \%$ & $13,0 \%$ & $3,6 \%$ & $3,4 \%$ & $2,9 \%$ \\
\hline & & $\begin{array}{l}\text { Jóvenes } \\
\text { emancipados }\end{array}$ & $26,8 \%$ & $28,7 \%$ & $29,3 \%$ & $18,1 \%$ & $17,5 \%$ & $20,6 \%$ & $5,9 \%$ & $4,7 \%$ & $5,3 \%$ \\
\hline & \multirow[t]{2}{*}{ Eslovenia } & Total población & $11,8 \%$ & $14,8 \%$ & $15,5 \%$ & $4,0 \%$ & $4,2 \%$ & $4,6 \%$ & $1,5 \%$ & $1,9 \%$ & $2,4 \%$ \\
\hline & & $\begin{array}{l}\text { Jóvenes } \\
\text { emancipados }\end{array}$ & $14,9 \%$ & $16,6 \%$ & $17,8 \%$ & $5,5 \%$ & $6,6 \%$ & $7,7 \%$ & $2,7 \%$ & $2,3 \%$ & $3,0 \%$ \\
\hline
\end{tabular}

Fuente: elaboración propia a partir de EUROSTAT, European Survey on Income and Living Conditions (EU SILC). 
Tabla 4. Aspectos del sistema de ayudas para el pago de la vivienda según grupo de edad (Europa, 2006-2011)

\begin{tabular}{|c|c|c|c|c|c|c|c|c|c|c|c|}
\hline & & & \multicolumn{3}{|c|}{$\begin{array}{l}\text { Porcentaje que } \\
\text { representan las ayudas } \\
\text { públicas para el pago de } \\
\text { la vivienda respecto al } \\
\text { total de costes de esta }\end{array}$} & \multicolumn{3}{|c|}{$\begin{array}{l}\text { Importe medio anual } \\
\text { de las ayudas públicas } \\
\text { dirigidas al pago de los } \\
\text { costes de la vivienda } \\
\text { (euros) }\end{array}$} & \multicolumn{3}{|c|}{$\begin{array}{l}\text { Porcentaje de personas } \\
\text { que reciben ayudas } \\
\text { públicas para el pago de } \\
\text { los costes de la vivienda }\end{array}$} \\
\hline & & & $\begin{array}{l}2006- \\
2007\end{array}$ & $\begin{array}{l}2008- \\
2009\end{array}$ & $\begin{array}{l}2010- \\
2011\end{array}$ & $\begin{array}{l}2006- \\
2007\end{array}$ & $\begin{array}{l}2008- \\
2009\end{array}$ & $\begin{array}{l}2010- \\
2011\end{array}$ & $\begin{array}{l}2006- \\
2007\end{array}$ & $\begin{array}{l}2008- \\
2009\end{array}$ & $\begin{array}{l}2010- \\
2011\end{array}$ \\
\hline \multirow{4}{*}{$\begin{array}{l}\text { Modelo } \\
\text { socialdemocrático }\end{array}$} & Islandia & Total población & $8,1 \%$ & $6,7 \%$ & $9,0 \%$ & 2.028 & 1.816 & 1.686 & $36,1 \%$ & $38,7 \%$ & $44,6 \%$ \\
\hline & & $\begin{array}{l}\text { Jóvenes } \\
\text { emancipados }\end{array}$ & $14,0 \%$ & $11,2 \%$ & $14,4 \%$ & 1.958 & 1.774 & 1.851 & $56,0 \%$ & $56,9 \%$ & $59,1 \%$ \\
\hline & Finlandia & Total población & $6,6 \%$ & $6,1 \%$ & $6,8 \%$ & 2.097 & 2.186 & 2.251 & $16,9 \%$ & $16,3 \%$ & $17,2 \%$ \\
\hline & & $\begin{array}{l}\text { Jóvenes } \\
\text { emancipados }\end{array}$ & $14,5 \%$ & $12,9 \%$ & $14,0 \%$ & 1.916 & 1.984 & 2.115 & $38,1 \%$ & $35,8 \%$ & $38,8 \%$ \\
\hline \multirow{8}{*}{$\begin{array}{l}\text { Modelo } \\
\text { corporativista }\end{array}$} & Francia & Total población & $11,7 \%$ & $10,1 \%$ & $8,2 \%$ & 2.316 & 2.294 & 2.059 & $26,3 \%$ & $25,8 \%$ & $24,3 \%$ \\
\hline & & $\begin{array}{l}\text { Jóvenes } \\
\text { emancipados }\end{array}$ & $15,1 \%$ & $13,4 \%$ & $12,2 \%$ & 1.989 & 1.926 & 2.118 & $39,9 \%$ & $40,5 \%$ & $37,1 \%$ \\
\hline & Bélgica & Total población & $0,2 \%$ & $0,2 \%$ & $0,2 \%$ & 1.677 & 2.336 & 1.589 & $0,9 \%$ & $0,7 \%$ & $0,7 \%$ \\
\hline & & $\begin{array}{l}\text { Jóvenes } \\
\text { emancipados }\end{array}$ & $0,4 \%$ & $0,2 \%$ & $0,4 \%$ & 1.643 & 975 & 1.620 & $1,8 \%$ & $1,2 \%$ & $1,9 \%$ \\
\hline & Austria & Total población & $1,2 \%$ & $1,4 \%$ & $1,4 \%$ & 1.706 & 1.825 & 1.874 & $3,9 \%$ & $4,8 \%$ & $5,0 \%$ \\
\hline & & $\begin{array}{l}\text { Jóvenes } \\
\text { emancipados }\end{array}$ & $1,6 \%$ & $2,0 \%$ & $2,3 \%$ & 1.509 & 1.598 & 1.691 & $6,0 \%$ & $7,9 \%$ & $8,9 \%$ \\
\hline & Luxemburgo & Total población & $1,4 \%$ & $2,3 \%$ & $4,0 \%$ & 1.506 & 2.273 & 1.692 & $7,8 \%$ & $7,0 \%$ & $15,4 \%$ \\
\hline & & $\begin{array}{l}\text { Jóvenes } \\
\text { emancipados }\end{array}$ & $2,3 \%$ & $3,0 \%$ & $3,8 \%$ & 2.443 & 2.855 & 1.908 & $9,2 \%$ & $8,0 \%$ & $14,8 \%$ \\
\hline \multirow[t]{4}{*}{ Modelo liberal } & Reino Unido & Total población & $6,0 \%$ & $6,1 \%$ & $6,4 \%$ & 5.546 & 4.724 & 4.914 & $11,6 \%$ & $12,2 \%$ & $13,1 \%$ \\
\hline & & $\begin{array}{l}\text { Jóvenes } \\
\text { emancipados }\end{array}$ & $5,8 \%$ & $5,7 \%$ & $7,2 \%$ & 5.140 & 4.622 & 5.078 & $11,0 \%$ & $11,7 \%$ & $14,3 \%$ \\
\hline & Irlanda & Total población & $8,2 \%$ & $9,3 \%$ & $10,5 \%$ & 1.635 & 1.826 & 1.897 & $22,3 \%$ & $24,2 \%$ & $25,4 \%$ \\
\hline & & $\begin{array}{l}\text { Jóvenes } \\
\text { emancipados }\end{array}$ & $6,1 \%$ & $6,1 \%$ & $8,2 \%$ & 3.585 & 3.870 & 3.821 & $14,9 \%$ & $15,3 \%$ & $18,6 \%$ \\
\hline \multirow{10}{*}{$\begin{array}{l}\text { Modelo } \\
\text { mediterráneo }\end{array}$} & Chipre & Total población & $1,7 \%$ & $1,5 \%$ & $1,9 \%$ & 5.124 & 5.976 & 7.533 & $2,9 \%$ & $2,4 \%$ & $3,2 \%$ \\
\hline & & $\begin{array}{l}\text { Jóvenes } \\
\text { emancipados }\end{array}$ & $2,7 \%$ & $3,2 \%$ & $3,4 \%$ & 7.388 & 9.047 & 11.501 & $4,9 \%$ & $5,2 \%$ & $5,6 \%$ \\
\hline & España & Total población & $0,5 \%$ & $0,5 \%$ & $0,6 \%$ & 4.111 & 1.903 & 2.123 & $1,0 \%$ & $1,2 \%$ & $1,5 \%$ \\
\hline & & $\begin{array}{l}\text { Jóvenes } \\
\text { emancipados }\end{array}$ & $1,2 \%$ & $1,1 \%$ & $1,6 \%$ & 4.027 & 2.205 & 1.934 & $2,6 \%$ & $3,2 \%$ & $5,1 \%$ \\
\hline & Grecia & Total población & $0,5 \%$ & $0,4 \%$ & $0,3 \%$ & 1.526 & 1.752 & 1.892 & $1,3 \%$ & $1,5 \%$ & $0,9 \%$ \\
\hline & & $\begin{array}{l}\text { Jóvenes } \\
\text { emancipados }\end{array}$ & $0,5 \%$ & $0,3 \%$ & $0,2 \%$ & 1.277 & 1.600 & 1.938 & $1,8 \%$ & $1,6 \%$ & $0,6 \%$ \\
\hline & Portugal & Total población & $1,1 \%$ & $1,1 \%$ & $1,0 \%$ & 533 & 472 & 469 & $7,6 \%$ & $8,3 \%$ & $6,5 \%$ \\
\hline & & $\begin{array}{l}\text { Jóvenes } \\
\text { emancipados }\end{array}$ & $2,3 \%$ & $1,7 \%$ & $2,3 \%$ & 607 & 554 & 459 & $15,4 \%$ & $11,9 \%$ & $10,7 \%$ \\
\hline & Italia & Total población & $0,4 \%$ & $0,5 \%$ & $0,5 \%$ & 1.277 & 1.735 & 1.073 & $1,7 \%$ & $2,1 \%$ & $2,3 \%$ \\
\hline & & $\begin{array}{l}\text { Jóvenes } \\
\text { emancipados }\end{array}$ & $0,6 \%$ & $0,7 \%$ & $0,9 \%$ & 1.315 & 1.551 & 1.101 & $2,6 \%$ & $3,3 \%$ & $4,4 \%$ \\
\hline
\end{tabular}


Tabla 4. Aspectos del sistema de ayudas para el pago de la vivienda según grupo de edad (Europa, 2006-2011) (continuación)

\begin{tabular}{|c|c|c|c|c|c|c|c|c|c|c|c|}
\hline & & & \multicolumn{3}{|c|}{$\begin{array}{l}\text { Porcentaje que } \\
\text { representan las ayudas } \\
\text { públicas para el pago de } \\
\text { la vivienda respecto al } \\
\text { total de costes de esta }\end{array}$} & \multicolumn{3}{|c|}{$\begin{array}{l}\text { Importe medio anual } \\
\text { de las ayudas públicas } \\
\text { dirigidas al pago de los } \\
\text { costes de la vivienda } \\
\text { (euros) }\end{array}$} & \multicolumn{3}{|c|}{$\begin{array}{l}\text { Porcentaje de personas } \\
\text { que reciben ayudas } \\
\text { públicas para el pago de } \\
\text { los costes de la vivienda }\end{array}$} \\
\hline & & & $\begin{array}{l}2006- \\
2007\end{array}$ & $\begin{array}{l}2008- \\
2009\end{array}$ & $\begin{array}{c}2010- \\
2011\end{array}$ & $\begin{array}{l}2006- \\
2007\end{array}$ & $\begin{array}{l}2008- \\
2009\end{array}$ & $\begin{array}{l}2010- \\
2011\end{array}$ & $\begin{array}{l}2006- \\
2007\end{array}$ & $\begin{array}{c}2008- \\
2009\end{array}$ & $\begin{array}{c}2010- \\
2011\end{array}$ \\
\hline \multirow{14}{*}{$\begin{array}{l}\text { Modelo de } \\
\text { transición }\end{array}$} & Estonia & Total población & $0,9 \%$ & $0,7 \%$ & $1,0 \%$ & 383 & 432 & 704 & $1,8 \%$ & $1,6 \%$ & $2,1 \%$ \\
\hline & & $\begin{array}{l}\text { Jóvenes } \\
\text { emancipados }\end{array}$ & $0,6 \%$ & $0,4 \%$ & $0,8 \%$ & 318 & 542 & 831 & $1,4 \%$ & $1,0 \%$ & $1,8 \%$ \\
\hline & Rep. Checa & Total población & $1,4 \%$ & $0,7 \%$ & $0,8 \%$ & 362 & 588 & 929 & $7,3 \%$ & $2,9 \%$ & $2,3 \%$ \\
\hline & & $\begin{array}{l}\text { Jóvenes } \\
\text { emancipados }\end{array}$ & $1,5 \%$ & $0,7 \%$ & $1,0 \%$ & 334 & 542 & 952 & $8,4 \%$ & $3,1 \%$ & $2,9 \%$ \\
\hline & Lituania & Total población & $0,5 \%$ & $0,4 \%$ & $0,7 \%$ & 111 & 177 & 214 & $3,8 \%$ & $3,8 \%$ & $3,5 \%$ \\
\hline & & $\begin{array}{l}\text { Jóvenes } \\
\text { emancipados }\end{array}$ & $0,4 \%$ & $0,1 \%$ & $0,8 \%$ & 157 & 321 & 173 & $2,3 \%$ & $1,9 \%$ & $3,3 \%$ \\
\hline & Letonia & Total población & $0,4 \%$ & $0,5 \%$ & $1,3 \%$ & 138 & 202 & 212 & $2,3 \%$ & $2,4 \%$ & $6,2 \%$ \\
\hline & & $\begin{array}{l}\text { Jóvenes } \\
\text { emancipados }\end{array}$ & $0,3 \%$ & $0,2 \%$ & $1,3 \%$ & 252 & 190 & 269 & $1,0 \%$ & $1,1 \%$ & $5,4 \%$ \\
\hline & Polonia & Total población & $1,7 \%$ & $1,2 \%$ & $0,7 \%$ & 374 & 449 & 416 & $5,7 \%$ & $4,1 \%$ & $2,5 \%$ \\
\hline & & $\begin{array}{l}\text { Jóvenes } \\
\text { emancipados }\end{array}$ & $1,4 \%$ & $1,0 \%$ & $0,8 \%$ & 328 & 416 & 453 & $5,5 \%$ & $3,9 \%$ & $2,8 \%$ \\
\hline & Hungría & Total población & $1,5 \%$ & $1,6 \%$ & $1,3 \%$ & 223 & 226 & 226 & $8,6 \%$ & $11,9 \%$ & $9,7 \%$ \\
\hline & & $\begin{array}{l}\text { Jóvenes } \\
\text { emancipados }\end{array}$ & $1,7 \%$ & $1,7 \%$ & $2,1 \%$ & 248 & 224 & 271 & $8,4 \%$ & $12,4 \%$ & $12,7 \%$ \\
\hline & Eslovenia & Total población & $0,3 \%$ & $0,2 \%$ & $0,1 \%$ & 984 & 1.042 & 611 & $0,8 \%$ & $0,6 \%$ & $0,7 \%$ \\
\hline & & $\begin{array}{l}\text { Jóvenes } \\
\text { emancipados }\end{array}$ & $0,5 \%$ & $0,2 \%$ & $0,2 \%$ & 1.181 & 994 & 895 & $1,3 \%$ & $0,8 \%$ & $0,7 \%$ \\
\hline
\end{tabular}

Fuente: elaboración propia a partir de EUROSTAT, European Survey on Income and Living Conditions (EU SILC). 